\title{
Bioprospecting Antimicrobials from Lactiplantibacillus plantarum: Key Factors Underlying Its Probiotic Action
}

\author{
Maria Teresa Rocchetti $\left.{ }^{1}{ }^{(}\right)$, Pasquale Russo ${ }^{2}$, Vittorio Capozzi ${ }^{3}{ }^{\circ}$, Djamel Drider ${ }^{4}{ }^{(0}$, Giuseppe Spano ${ }^{2}$ \\ and Daniela Fiocco $1, *$ (1)
}

1 Department of Clinical and Experimental Medicine, University of Foggia, 71122 Foggia, Italy; mariateresa.rocchetti@unifg.it

2 Department of Agriculture Food Natural Science Engineering (DAFNE), University of Foggia, 71122 Foggia, Italy; pasquale.russo@unifg.it (P.R.); giuseppe.spano@unifg.it (G.S.)

3 Institute of Sciences of Food Production, National Research Council (CNR) of Italy, c/o CS-DAT, Via Michele Protano, 71122 Foggia, Italy; vittorio.capozzi@ispa.cnr.it

4 UMR Transfrontalière BioEcoAgro1158, Univ. Lille, INRAE, Univ. Liège, UPJV, YNCREA, Univ. Artois, Univ. Littoral Côte d'Opale, ICV-Institut Charles Viollette, F-59000 Lille, France; djamel.drider@univ-lille.fr

* Correspondence: daniela.fiocco@unifg.it

Citation: Rocchetti, M.T.; Russo, P.; Capozzi, V.; Drider, D.; Spano, G.; Fiocco, D. Bioprospecting

Antimicrobials from Lactiplantibacillus plantarum: Key Factors Underlying Its Probiotic Action. Int. J. Mol. Sci. 2021, 22, 12076. https://doi.org/10.3390/ ijms222112076

Academic Editor: Hanne Frøkiær

Received: 30 September 2021

Accepted: 5 November 2021

Published: 8 November 2021

Publisher's Note: MDPI stays neutral with regard to jurisdictional claims in published maps and institutional affiliations.

Copyright: (c) 2021 by the authors. Licensee MDPI, Basel, Switzerland. This article is an open access article distributed under the terms and conditions of the Creative Commons Attribution (CC BY) license (https:// creativecommons.org/licenses/by/ $4.0 /)$.

\begin{abstract}
Lactiplantibacillus plantarum (L. plantarum) is a well-studied and versatile species of lactobacilli. It is found in several niches, including human mucosal surfaces, and it is largely employed in the food industry and boasts a millenary tradition of safe use, sharing a long-lasting relationship with humans. L. plantarum is generally recognised as safe and exhibits a strong probiotic character, so that several strains are commercialised as health-promoting supplements and functional food products. For these reasons, L. plantarum represents a valuable model to gain insight into the nature and mechanisms of antimicrobials as key factors underlying the probiotic action of health-promoting microbes. Probiotic antimicrobials can inhibit the growth of pathogens in the gut ensuring the intestinal homeostasis and contributing to the host health. Furthermore, they may be attractive alternatives to conventional antibiotics, holding potential in several biomedical applications. The aim of this review is to investigate the most relevant papers published in the last ten years, bioprospecting the antimicrobial activity of characterised probiotic L. plantarum strains. Specifically, it focuses on the different chemical nature, the action spectra and the mechanisms underlying the bioactivity of their antibacterial and antiviral agents. Emerging trends in postbiotics, some in vivo applications of L. plantarum antimicrobials, including strengths and limitations of their therapeutic potential, are addressed and discussed.
\end{abstract}

Keywords: Lactiplantibacillus plantarum; lactic acid bacteria; probiotics; antibacterial extracellular compound; antiviral extracellular compound; probiosis; postbiotic; bacteriocin; plantaricin; organic acid; cell-free supernatant

\section{Introduction}

Lactiplantibacillus plantarum (L. plantarum), previously known as Lactobacillus plantarum, is a versatile species of lactobacilli. This subgroup of lactic acid bacteria (LAB) encompasses prokaryotes present in a range of diverse environments, including the gastrointestinal tract (GIT) of mammals, vaginal mucosa, food matrices, soil, and vegetable-associated niches. In this light, L. plantarum, in reason of a flexible behaviour, is found in association with all these niches (in several cases, with a dominant character) and is largely employed as starter cultures in the food industry. Selected L. plantarum strains are used to promote and/or carry-over fermentation processes that are functional to food production addressed to human consumption [1]. For its capacity to ferment and preserve food, enhancing its sensory properties and nutritional value, L. plantarum boasts a millenary tradition of safe use and thus shares a long-lasting relationship with humans. Moreover, like most 
lactobacilli, this species is generally recognized as safe (GRAS) and has been included by EFSA in the list of microorganisms with Qualified Presumption of Safety (QPS) [2]. More recently, the connection between humans and L. plantarum has been further strengthened by experimental evidences that highlight the probiotic character of several strains [3], some of which are commercialised as health-promoting supplements and functional food products [4]. For all the properties mentioned above, this species represents a good model to deepen the nature and mechanisms of antimicrobials as key factors related to probiotic action of lactobacilli. The status of probiotics connotes microorganisms endowed with the ability to confer health benefits on the host upon ingestion in adequate amounts [5]; this depends on a set of microbial properties which include, among others, the aptitude to survive to the harsh conditions imposed by the human GIT, the capacity to colonise, at least transiently, the intestinal mucosa, to reinforce gut barrier function, to preserve the balance of the gut microbiota and prevent dysbiosis, to stimulate immune responses by interacting with host defence cells, to support digestive functions, and to synthesise vitamins, short-chain fatty acids and/or bioactive molecules that may be helpful for the host [6-9]. Likewise, the debated term "postbiotic" has been emerging recently to indicate inanimated microbial cells, cellular components and/or metabolites that promote the observed health benefit [10-12].

In this regard, the production of antimicrobials is associated with some important probiotic properties, as well as relevant protechnological features of LAB in food and beverage applications [13-16]. Indeed, the antimicrobial compounds derived from the lactobacilli colonising the gut can keep under control the growth of potential pathogens and opportunistic species, thus playing a relevant part in the complex net of relationships that ensure the homeostasis of the intestinal ecosystem, and contributing to the host health [17-19]. Moreover, by antagonising common food spoilage/contaminating microbes, antimicrobials from starter lactobacilli ensure food safety and prolonged bio-preservation [20-22].

The main antimicrobial chemicals produced by lactobacilli comprise (i) ribosomally synthesised peptides, i.e., bacteriocins [23] and (ii) metabolic by-products of various chemical nature, such as hydrogen peroxide $\left(\mathrm{H}_{2} \mathrm{O}_{2}\right)$ [24], lactic acid and other organic acids [25], phenolic compounds [26,27], etc. While bacteriocins typically exhibit selective and targetspecific antagonistic activity [23], the latter group comprise molecules that generally act rather aspecifically in inhibiting the growth of competitor species (Figure 1). Taking into account the worldwide healthcare emergency of the increasing (multi) drug resistance of infectious agents, the antimicrobials produced by probiotic lactobacilli, especially bacteriocins, may be suitable alternatives to conventional antibiotics and thus hold great potential in several biomedical applications $[18,28,29]$.

In this review, we aim to survey some of the most relevant and recent papers, among those published in the last decade, bioprospecting the antimicrobial activity of characterised probiotic L. plantarum strains. Specifically, we focus on the different chemical nature of the antibacterial and antiviral agents produced, their action spectra, and the mechanisms underlying their bioactivity. Furthermore, we highlight some in vivo applications of these compounds, discussing the limitations of their therapeutical potential. 


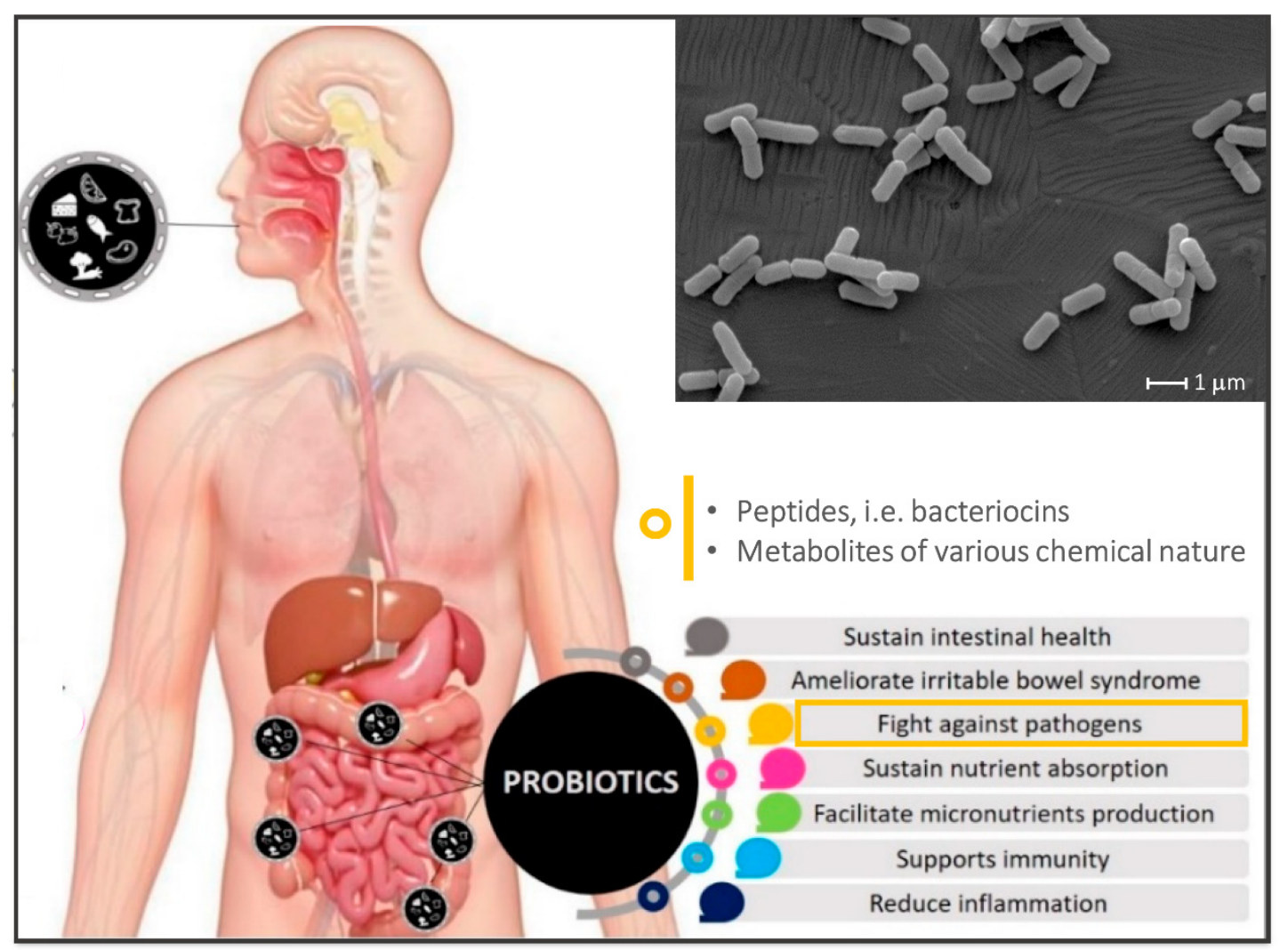

Figure 1. Conceptualisation of the intake of probiotic-containing foods/beverages and of the most investigated beneficial properties exerted by probiotics, with a specific emphasis on the antimicrobial chemicals produced by lactobacilli. The indicated probiotic mechanisms are putative, not always sufficiently proven, and may depend on bacterial number, host gut microbiome composition and the specific probiotic strain. Image partially reproduced from Pop et al. [30] (copyright 2020 MDPI). In grey, an original picture of Lactiplantibacillus plantarum WCFS1 cells imaged by scanning electron microscope (SEM).

\section{Emerging Trends in Probiosis, Postbiotics and Antimicrobials}

While the terms probiotics, prebiotics, and synbiotics have been extensively defined in the last two decades and consensus documents have been provided by experts for each of them [5,31,32], the new concept of postbiotic is taking shape as an important microorganism-derived tool to promote health [10-12]. The need for a more precise terminology derived from observing the potential beneficial effect of non-viable microbial cells or effectors molecules contained, for example, in fer-mented foods (especially after prolonged storage) or in probiotic preparations (especially at the end of shelf life). The antimicrobial and antiviral activity exerted by beneficial microorganisms, such as L. plantarum, depends on a variety of molecules (organic acids, peptides, short-chain fatty acids (SCFA) and other antagonistic metabolites) that act with different action mechanisms and, sometimes, synergically produce the final bactericidal or bacteriostatic effects against the target microbes. Likewise, bacterial lysates have been shown to have some health benefits [33]. However, a precise distinction between the efficacy of non-viable beneficial bacteria, their growth products and their end-products on overall host health is not yet well defined, as each could have a beneficial role individually or in combination with the others. Very recently, postbiotics have been defined as a "preparation of inanimate microorganisms and/or their components that confers a health benefit on the hosts" [10], including in this concept the killed microbial cells with or without metabolites and excluding purified products (i.e., proteins, peptides, exopolysaccharides (EPS), SCFAs) [10]. The specific killed microorganism, the matrix and the inactivation method should be accurately indicated in the postbiotic definition. Until recently, the term postbiotics referred also to soluble factors secreted by live bacteria or released after bacterial lysis, also known simply as cell-free 
supernatants (CFS), i.e., quite heterogeneous mixtures including SCFAs, cellular enzymes, peptides, teichoic acids, peptidoglycan-derived muropeptides, EPS, cell surface proteins, vitamins, plasmalogens, and organic acids, which could have the same health beneficial effects of the strain that generated them [34]. However, a precise boundary line between what is currently defined postbiotic and what is not (i.e., CFS) is actually very difficult to delineate because some chemically synthesised compounds and/or metabolites might be present in both viable and not viable microbial cell preparations (Figure 2). Likewise, other scientists have pointed to some inconsistencies and ambiguities associated with the recently proposed re-definition of postbiotics [11]. Therefore, we wonder whether microbiologists should coin a new term to correctly define a probiotic bacterial CFS, which in most research work, is filtered to eliminate cells and cellular debris. Nonetheless, according to the International Scientific Association of Probiotics and Prebiotics (ISAPP), the term CFS is sufficiently defined as such and further definitions are not deemed as necessary [12].

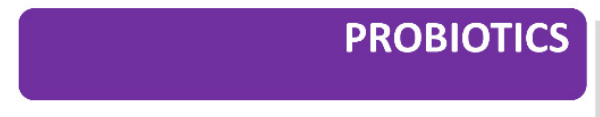

LIVE PROBIOTIC CELLS (VIABLE)

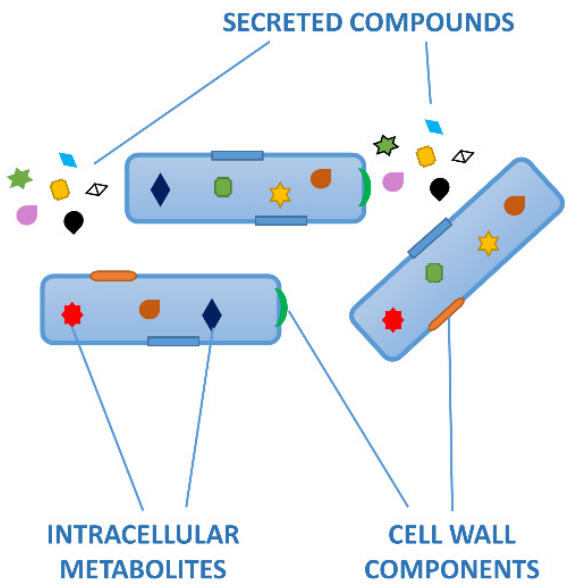

\section{POSTBIOTICS}

AND RELEASED METABOLITES/SECRETED COMPOUNDS

DEAD PROBIOTIC CELLS (NON-VIABLE)

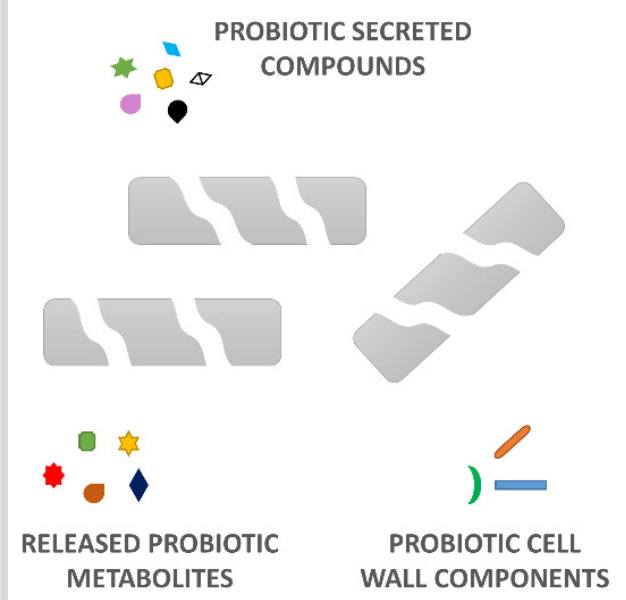

Figure 2. Graphic schematisation of the concepts of probiotic (on the left), postbiotic and released metabolites/secreted compounds (on the right). This review focuses on L. plantarum secreted compounds (i.e., CFS or isolated compounds from CFS) with antimicrobial activity.

In this context, not yet clearly defined, we gathered and reported in temporal order (Table 1) the data from the last decade on the chemical nature of compounds with antibacterial and/or antiviral activity as found in the CFS of probiotic L. plantarum strains. In addition, the investigated action mechanisms of the single antimicrobial substances are reported. We realise from these studies that, despite trying to understand and dissect the action mechanism of the single antimicrobial compound, the overall mechanisms of complex mixtures underlying food preservation and human/animal health are still far from being fully understood. 
Table 1. Probiotic L. plantarum strains with documented in vitro antibacterial activity.

\begin{tabular}{|c|c|c|c|c|c|}
\hline Isolation Niche & $\begin{array}{l}\text { Strain } \\
\text { Name }\end{array}$ & $\begin{array}{c}\text { Type of } \\
\text { Antimicrobial }\end{array}$ & $\begin{array}{l}\text { Investigated Action } \\
\text { Mechanism }\end{array}$ & $\begin{array}{l}\text { Strong Antimicrobial Activity/ } \\
\text { Inhibited Bacterial Species }\end{array}$ & Reference \\
\hline Fermented cocoa & $\begin{array}{l}\text { Lp }^{1} 03 \\
\text { Lp } 289 \\
\text { Lp } 291\end{array}$ & $\begin{array}{l}\text { Organic acid (lactic } \\
\text { acid) }\end{array}$ & n.i. ${ }^{2}$ & $\begin{array}{l}\text { Gardnerella vaginalis, Neisseria } \\
\text { gonorrhoeae }\end{array}$ & $\begin{array}{l}\text { das Neves } \\
\text { Selis N, } \\
2021\end{array}$ \\
\hline $\begin{array}{l}\text { Yoghurt } \\
\text { fermented by } \\
\text { koumiss }\end{array}$ & Lp RUB1 & Class II bacteriocin & n.i. & Bacillus cereus ATCC 14579 & Wu A, 2021 \\
\hline Cheese & Lp 60FHE & $\begin{array}{l}\text { Biosurfactant: } \\
\text { glycoprotein }\end{array}$ & Cell membrane lysis & $\begin{array}{c}\text { Staphylococcus epidermidis ATCC } \\
\text { 12228, Microcccus luteus ATCC } \\
\text { 10240, Escherichia coli ATCC10536, } \\
\text { Pseudomonas aeruginosa ATCC } \\
\text { 9027, Salmonella typhimurium, } \\
\text { Enterobacter aerogenes 9805, } \\
\text { Serratia marcescens 98027, } \\
\text { Staphylococcus aureus ATCC 29737, } \\
\text { Bacillus. pumilis ATCC 14884, } \\
\text { Bacillus subtilis }\end{array}$ & $\begin{array}{l}\text { Sakr AE, } \\
2021\end{array}$ \\
\hline $\begin{array}{l}\text { Ghanaian } \\
\text { traditionally } \\
\text { fermented cow } \\
\text { milk }\end{array}$ & $\begin{array}{l}\text { Lp NL27 } \\
\text { Lp PA27 }\end{array}$ & $\mathrm{CFS}^{3}$ & n.i. & E. coli, S. Typhimurium & $\begin{array}{l}\text { Motey GA, } \\
2021\end{array}$ \\
\hline $\begin{array}{l}\text { Indonesian } \\
\text { traditional } \\
\text { fermented meat }\end{array}$ & Lp S34 & Plantaricin S34 & n.i. & $\begin{array}{l}\text { Enteropathogenic E. coli (EPEC) } \\
\text { K1.1., S. aureus, Salmonella typhosa, } \\
\text { S typhimurium, Proteus sp. }\end{array}$ & $\begin{array}{l}\text { Ahaddin } \\
\text { AY, } 2021\end{array}$ \\
\hline $\begin{array}{l}\text { Nem 'chua' } \\
\text { (vietnamese } \\
\text { sausage) }\end{array}$ & Lp B21 & $\begin{array}{l}\text { Plantacyclin } \\
\text { B21AG }\end{array}$ & $\begin{array}{l}\text { Deduced by } \\
\text { comparisons with } \\
\text { other circular } \\
\text { bacteriocins using } \\
\text { multiple sequence } \\
\text { alignment: insertion } \\
\text { into the } \\
\text { phospholipid bilayer } \\
\text { of the target cell } \\
\text { membrane }\end{array}$ & $\begin{array}{l}\text { Clostridium perfringens 52/6-1, } \\
\text { Listeria monocytogenes 192/1-2 } \\
\text { ACM } 3173\end{array}$ & $\begin{array}{l}\text { Golneshin } \\
\text { A, } 2020\end{array}$ \\
\hline Kimchi & $\begin{array}{c}\text { Lp } \\
\text { NIBR97 }\end{array}$ & Plantaricin 3,5 & $\begin{array}{c}\text { Cellular lysis via } \\
\text { pore formation in } \\
\text { bacterial membranes } \\
\text { by cellular } \\
\text { penetrating peptides }\end{array}$ & $\begin{array}{c}\text { Salmonella enterica Serovar } \\
\text { Enteritidis }\end{array}$ & $\begin{array}{l}\text { Kim SW, } \\
2020\end{array}$ \\
\hline Sauerkraut & Lp SF9C & Plantaricin & 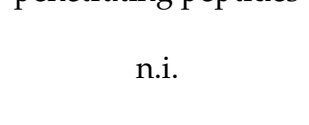 & $\begin{array}{l}\text { L. monocytogenes ATCC }{ }^{\circledR} 19111^{\mathrm{TM}} \text {, } \\
\text { S. aureus } 3048 \text {, S. enterica serovar } \\
\text { Typhimurium FP1, E. coli } 3014\end{array}$ & $\begin{array}{l}\text { Butorac K, } \\
\quad 020\end{array}$ \\
\hline Kimchi & Lp EM & $\begin{array}{l}\text { Plantaricin and } \\
\text { bovicin }\end{array}$ & n.i. & $\begin{array}{l}\text { Vibrio parahaemolyticus ATCC } \\
\text { 17802, P. aeruginosa, S. enterica } \\
\text { serovar Typhi, B. cereus }\end{array}$ & $\begin{array}{c}\text { Kim E, } 2020 \\
\text { Choi EA, } \\
2015\end{array}$ \\
\hline Yoghurt & Lp ZX27 & $\begin{array}{l}\text { Plantaricin } \\
\quad \text { CFS }\end{array}$ & $\begin{array}{l}\text { n.i. } \\
\text { Reduction in G. } \\
\text { vaginalis biofilm } \\
\text { formation and } \\
\text { preformed biofilm; } \\
\text { suppressing the } \\
\text { expression of genes } \\
\text { related to G. vaginalis } \\
\text { pathogenicity }\end{array}$ & E. coli, G. vaginalis & $\begin{array}{l}\text { Qian Z, } \\
2020 \\
\text { Qian Z, } \\
2021\end{array}$ \\
\hline $\begin{array}{l}\text { Intestines of a } \\
\text { turbot }\end{array}$ & Lp-12 & EPSs 4 & $\begin{array}{l}\text { Inhibition of biofilm } \\
\text { formation }\end{array}$ & Shigella flexneri & $\begin{array}{l}\text { Song Y, } \\
2020\end{array}$ \\
\hline
\end{tabular}


Table 1. Cont.

\begin{tabular}{|c|c|c|c|c|c|}
\hline Isolation Niche & $\begin{array}{l}\text { Strain } \\
\text { Name }\end{array}$ & $\begin{array}{c}\text { Type of } \\
\text { Antimicrobial }\end{array}$ & $\begin{array}{c}\text { Investigated Action } \\
\text { Mechanism }\end{array}$ & $\begin{array}{l}\text { Strong Antimicrobial Activity/ } \\
\text { Inhibited Bacterial Species }\end{array}$ & Reference \\
\hline $\begin{array}{l}\text { 'Dahi', a fermented } \\
\text { milk product }\end{array}$ & $\begin{array}{l}\text { Lp } \\
\text { DHCU70, } \\
\text { Lp DKP1 }\end{array}$ & $\begin{array}{l}\text { NC8 type of } \\
\text { bacteriocin }\end{array}$ & $\begin{array}{l}\text { Inhibition of cell } \\
\text { wall biosynthesis }\end{array}$ & Kocuria rhizophila & $\begin{array}{c}\text { Goel A, } \\
2020\end{array}$ \\
\hline Infant's feces & Lp zrx03 & Bacteriocin & n.i. & $\begin{array}{l}\text { S. aureus ATCC 25923, E. coli } \\
\text { JM109 ATCC 67387, B. subtilis } \\
\text { CICC 10002, Bacillus anthracis } \\
\text { CICC 20443, Salmonella CMCC } 541\end{array}$ & Lei S, 2020 \\
\hline $\begin{array}{l}\text { Human oral } \\
\text { cavities }\end{array}$ & Lp 108 & CFS & $\begin{array}{l}\text { Inhibited growth } \\
\text { and biofilm } \\
\text { formation by } \\
\text { preventing microbial } \\
\text { coaggregation; } \\
\text { inhibit the adhesion } \\
\text { of Streptococcus } \\
\text { mutans and Candida } \\
\text { albicans to solid } \\
\text { surfaces }\end{array}$ & Streptococcus mutans UA159 & $\begin{array}{l}\text { Srivastava } \\
\text { N, } 2020\end{array}$ \\
\hline $\begin{array}{l}\text { Slovak raw sheep } \\
\text { milk cheese }\end{array}$ & $\begin{array}{l}\text { Lp L5, } \\
\text { L19, L20, } \\
\text { and L22 }\end{array}$ & $\begin{array}{l}\text { Partially purified } \\
\text { bacteriocins }\end{array}$ & n.i. & L. monocytogenes, S. aureus & $\begin{array}{l}\text { Vataščinová } \\
\text { T, } 2020\end{array}$ \\
\hline $\begin{array}{l}\text { Weaned piglet } \\
\text { faeces }\end{array}$ & Lp ZA3 & $\begin{array}{l}\text { lactic acid and } \\
\text { acetic acid }\end{array}$ & n.i. & Enterotoxigenic E. coli (ETEC) K88 & $\begin{array}{l}\text { Wang W, } \\
2020\end{array}$ \\
\hline $\begin{array}{l}\text { Stool human } \\
\text { samples }\end{array}$ & Lp 69.1 & CFS & n.i. & $\begin{array}{c}\text { ETEC and Enteroaggregative } E . \\
\text { coli }(E A E C)\end{array}$ & $\begin{array}{l}\text { Pazhoohan } \\
\text { M, } 2020\end{array}$ \\
\hline $\begin{array}{l}\text { Faeces of healthy } \\
\text { infants }\end{array}$ & Lp 34-5 & CFS (pH acid) & n.i & $\begin{array}{l}\text { S. flexneri ATCC 12022, ETEC } \\
\text { H10407 enteropathogenic bacteria }\end{array}$ & $\begin{array}{l}\text { Pazhoohan } \\
\text { M, } 2020\end{array}$ \\
\hline $\begin{array}{l}\text { Wild-type fruits of } \\
\text { Theobroma } \\
\text { grandiflorum (white } \\
\text { coffee), and Malus } \\
\text { sp. }\end{array}$ & $\begin{array}{l}\text { Lp } \\
\text { UTNGt2, } \\
\text { Lp } \\
\text { UTNCys5- } \\
\quad 4\end{array}$ & $\begin{array}{l}\text { Gt2 peptides, } \\
\text { Cys5-4 peptide }\end{array}$ & $\begin{array}{l}\text { Cell membrane } \\
\text { disruption and } \\
\text { leaking of } \\
\text { cytoplasmic } \\
\beta \text {-galactosidase, } \\
\text { RNA and DNA } \\
\text { molecules. Binding } \\
\text { and interacting with } \\
\text { pathogen genomic } \\
\text { DNA }\end{array}$ & $\begin{array}{l}\text { S. enterica subsp. enterica ATCC } \\
\text { 51741, E. coli ATCC 25922, Shigella } \\
\text { sonnei ATCC 25931 }\end{array}$ & $\begin{array}{l}\text { Tenea GN, } \\
2020,2019 a, \\
2019 b\end{array}$ \\
\hline Faeces of infants & Lp N20 & Organic acid & n.i. & $\begin{array}{c}\text { Yersinia enterocolitica ATCC } 23715 \text {, } \\
\text { S. flexneri ATCC 12022, S.enterica } \\
\text { ATCC 9270, enteropathogenic E. coli } \\
\text { (EPEC) ATCC } 43887\end{array}$ & $\begin{array}{l}\text { Jomehzadeh } \\
\text { N, } 2020\end{array}$ \\
\hline Kimchi & $\begin{array}{c}\text { Lp } \\
\text { KU200656 }\end{array}$ & CFS & $\begin{array}{l}\text { Downregulation of } \\
\text { the expression of } \\
\text { pathogen's } \\
\text { biofilm-related genes }\end{array}$ & $\begin{array}{c}\text { S. aureus ATCC } 6538, \mathrm{~L} . \\
\text { monocytogenes ATCC } 15313, \text { E. coli } \\
\text { ATCC } 25922\end{array}$ & Lee JE, 2020 \\
\hline Honey & $\begin{array}{l}\text { Lp H46, } \\
\text { H47, and } \\
\text { H59 }\end{array}$ & CFS & n.i & $\begin{array}{l}\text { S. flexneri ATCC } 12022, \text { S. aureus } \\
\text { ATCC 25923, S. enteritidis F17, } \\
\text { EPEC E2348/69, E. coli O157 H7 } \\
\text { EDL 933, B. cereus D14 }\end{array}$ & $\begin{array}{l}\text { Lashani E, } \\
\quad 2020\end{array}$ \\
\hline
\end{tabular}


Table 1. Cont.

\begin{tabular}{|c|c|c|c|c|c|}
\hline Isolation Niche & $\begin{array}{l}\text { Strain } \\
\text { Name }\end{array}$ & $\begin{array}{c}\text { Type of } \\
\text { Antimicrobial }\end{array}$ & $\begin{array}{l}\text { Investigated Action } \\
\text { Mechanism }\end{array}$ & $\begin{array}{l}\text { Strong Antimicrobial Activity/ } \\
\text { Inhibited Bacterial Species }\end{array}$ & Reference \\
\hline $\begin{array}{l}\text { Faeces of healthy } \\
\text { infants }\end{array}$ & Lp ZJ316 & $\begin{array}{l}\text { L-PLA }^{5} \\
\text { Plantaricin ZJ316 } \\
\text { Plantaricin NC8 }\end{array}$ & $\begin{array}{c}\text { Membrane } \\
\text { destruction and } \\
\text { DNA binding } \\
\text { n.i. } \\
\text { Cell membrane } \\
\text { permeabilization } \\
\text { and disruption }\end{array}$ & $\begin{array}{c}\text { S.enterica subsp. enterica ATCC } \\
\text { 14028. } \\
\text { L. monocytogenes, Listeria } \\
\text { welshimeri, E. coli JM109, } \\
\text { Pseudomonas putida ATCC 23288, S. } \\
\text { enterica ZJJK18. } \\
\text { S. enterica, S. typhimurium, } \\
\text { Salmonella paratyphi-A, S. } \\
\text { paratyphi-B, Micrococcus luteus } \\
\text { CGMCC 1.193, V. parahaemolyticus, } \\
\text { Staphylococcus epidermidis }\end{array}$ & $\begin{array}{c}\text { Zhou Q, } \\
2020 \\
\text { Chen L, } \\
2018 \\
\text { Jiang H, } \\
2018 \\
\text { Jiang H, } \\
2016\end{array}$ \\
\hline Sauerkraut & $\begin{array}{l}\text { Lp NRRL } \\
\text { B-4496 }\end{array}$ & $\begin{array}{l}\text { Proteinaceous } \\
\text { compound } \\
\text { CFS (acid) }\end{array}$ & 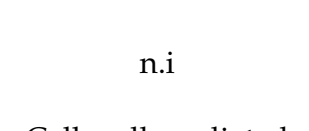 & $\begin{array}{l}\text { L. monocytogenes } \\
\text { Methicillin resistant S. aureus } \\
(M R S A), \text { L. monocytogenes, E. coli }\end{array}$ & $\begin{array}{l}\text { Arrioja- } \\
\text { Bretón D, } \\
2020\end{array}$ \\
\hline $\begin{array}{l}\text { Pork } \\
\text { minced meat }\end{array}$ & $\begin{array}{c}\text { Lp } \\
\text { USM8613 }\end{array}$ & $\begin{array}{c}\text { Transglycosylase } \\
\text { and } \\
\text { glyceraldehyde-3- } \\
\text { phosphate } \\
\text { dehydrogenase } \\
\text { (GADPH) }\end{array}$ & $\begin{array}{l}\text { Cell wall-mediated } \\
\text { killing mechanism; } \\
\text { GADPH penetrates } \\
\text { into S. aureus cells, } \\
\text { inducing the } \\
\text { overexpression of } \\
\text { autolysis regulators }\end{array}$ & S. aureus & $\begin{array}{l}\text { Ong JS, } \\
2019\end{array}$ \\
\hline Vaginal microbiota & Lp GF011 & CFS (acid pH) & n.i. & $\begin{array}{l}\text { Uropathogens: S. aureus sp. GF01, } \\
\text { P. aeruginosa GF01, Klebsiella sp. } \\
\text { GF01 }\end{array}$ & $\begin{array}{l}\text { ADEOSHUN } \\
\text { FG, } 2019\end{array}$ \\
\hline $\begin{array}{l}\text { Yoghurt, } \\
\text { Fermentation of } \\
\text { millet and urum }\end{array}$ & $\begin{array}{l}\text { Lp P1, } \\
\text { S11, and } \\
\text { M7 }\end{array}$ & $\begin{array}{c}\text { Organic acid } \\
\text { (lactic, acetic, } \\
\text { tartaric and malic } \\
\text { acids) }\end{array}$ & n.i. & E. coli and S. typhimurium & $\begin{array}{l}\mathrm{Hu} \mathrm{CH}, \\
2019\end{array}$ \\
\hline Kimchi & $\begin{array}{l}\text { Lp } \\
\text { SPC-SNU } \\
72-2\end{array}$ & Organic acid & n.i & $\begin{array}{c}\text { E. coli O157, L. monocytogenes, } S . \\
\text { typhimurium, H. pylori }\end{array}$ & $\begin{array}{l}\text { Park DM, } \\
2019\end{array}$ \\
\hline $\begin{array}{c}\text { Tarkhineh } \\
\text { human faeces } \\
\text { Lighvan cheese }\end{array}$ & $\begin{array}{l}\text { Lp PT10 } \\
\text { Lp PF11 } \\
\text { Lp PL4 }\end{array}$ & Bacteriocins & n.i & E. coli O157:H7, S. typhimurium & $\begin{array}{l}\text { Joghataei } \\
\text { M, } 2019\end{array}$ \\
\hline Kimchi & $\stackrel{\text { Lp }}{\text { LMT1-48 }}$ & $\begin{array}{c}\text { SCFA }^{6} \\
\text { (hypothesised) }\end{array}$ & n.i & E. cloacae & $\begin{array}{l}\text { Choi WJ, } \\
2019\end{array}$ \\
\hline $\begin{array}{l}\text { Sorghum beer } \\
\text { Fruits and } \\
\text { vegetables from } \\
\text { Pakistan }\end{array}$ & $\begin{array}{l}\text { Lp } 423 \\
\text { Lp AS-4, } \\
\text { AS-14 }\end{array}$ & Plantaricin 423 & $\begin{array}{l}\text { n.i } \\
\text { n.i. }\end{array}$ & $\begin{array}{c}\text { L. monocytogenes } \\
\text { Listeria innocua, E. coli EC10, L. } \\
\text { monocytogenes DPC } 6179\end{array}$ & $\begin{array}{l}\text { van Zyl WF, } \\
2019 \\
\text { Manzoor A, } \\
2019\end{array}$ \\
\hline $\begin{array}{l}\text { Artisanal milk } \\
\text { cheese }\end{array}$ & $\begin{array}{l}\text { Lp ATCC } \\
8014\end{array}$ & $\begin{array}{l}\text { CFS (pH acid) } \\
\text { Bacteriocin } \\
\text { Bacteriocin }\end{array}$ & $\begin{array}{c}\text { n.i } \\
\text { n.i } \\
\text { Growth inhibitory } \\
\text { activity against } \\
\text { planktonic cells; } \\
\text { inhibition of biofilm } \\
\text { formation } \\
\text { Inhibits adhesion } \\
\text { and biofilm } \\
\text { formation by } \\
\text { interfering with AI-2 } \\
\text { signalling molecules } \\
\text { and reducing } \\
\text { expression of } \\
\text { biofilm-related genes }\end{array}$ & $\begin{array}{l}\text { Clostridium butyricum, Clostridium } \\
\text { difficile, C. perfringens } \\
\text { S. aureus, S. marcenses }\end{array}$ & $\begin{array}{l}\text { Monteiro } \\
\text { CRM, } 2019 \\
\text { Fu T, } 2017 \\
\text { Shahandashti } \\
\text { RV, } 2016\end{array}$ \\
\hline
\end{tabular}


Table 1. Cont.

\begin{tabular}{|c|c|c|c|c|c|}
\hline Isolation Niche & $\begin{array}{l}\text { Strain } \\
\text { Name }\end{array}$ & $\begin{array}{c}\text { Type of } \\
\text { Antimicrobial }\end{array}$ & $\begin{array}{l}\text { Investigated Action } \\
\text { Mechanism }\end{array}$ & $\begin{array}{l}\text { Strong Antimicrobial Activity/ } \\
\text { Inhibited Bacterial Species }\end{array}$ & Reference \\
\hline Pineapple & $\begin{array}{l}\text { Lp NRIC } \\
149\end{array}$ & Plantaricin 149 & $\begin{array}{l}\text { Carpet-like model of } \\
\text { interaction with } \\
\text { Gram + membrane }\end{array}$ & Listeria and Staphylococcus genera & $\begin{array}{l}\text { Kumagai } \\
\text { PS, } 2019\end{array}$ \\
\hline $\begin{array}{c}\text { Faeces of healthy } \\
\text { humans }\end{array}$ & $\begin{array}{c}\text { Lp } \\
\text { PBS067 }\end{array}$ & Plantaricin P1053 & n.i. & S. aureus, E. coli & $\begin{array}{c}\text { De Giani A, } \\
2019\end{array}$ \\
\hline Koumiss & $\begin{array}{c}\text { Lp } \\
\text { MXG-68 }\end{array}$ & $\begin{array}{l}\text { Plantaricin } \\
\text { MXG-68 }\end{array}$ & $\begin{array}{l}\text { Bactericidal mode of } \\
\text { action }\end{array}$ & $\begin{array}{c}\text { L. monocytogenes ATCC } 15313, \text { B. } \\
\text { cereus ATCC } 11788, \text { E. coli ATCC } \\
\text { 25922, and S. typhimurium ATCC } \\
14028 .\end{array}$ & $\begin{array}{c}\text { Man L, } \\
2019\end{array}$ \\
\hline MTCC & $\begin{array}{l}\text { Lp subsp. } \\
\text { argen- } \\
\text { toratensis } \\
\quad \text { SJ33 }\end{array}$ & $\begin{array}{l}\text { Bacteriocin F1 and } \\
\text { F2 }\end{array}$ & $\begin{array}{l}\text { Bactericidal activity } \\
\text { on } S \text {. aureus by } \\
\text { membrane pore } \\
\text { formation and } \\
\text { leakage of cellular } \\
\text { contents; antibiofilm } \\
\text { activity for } P \text {. } \\
\text { aeruoinos } a\end{array}$ & $\begin{array}{l}\text { P. aeruginosa and S. aureus, } \\
\text { Aeromonas hydrophila, Clostridium } \\
\text { sporogenes, C. perfringens, E. coli, } \\
\text { Klebsiella pneumoniae }\end{array}$ & $\begin{array}{l}\text { Mohapatra } \\
\text { AR, } 2019\end{array}$ \\
\hline $\begin{array}{l}\text { Faeces of breastfed } \\
\text { infant }\end{array}$ & Lp F-10 & $\begin{array}{l}\text { CFS (acid pH), } \\
\text { EPSs }\end{array}$ & $\begin{array}{l}\text { Reduced } \\
\text { quorum-sensing } \\
\text { signals needed for } \\
\text { biofilm formation, } \\
\text { CFS might modify } \\
\text { the target surface, } \\
\text { causing a reduction } \\
\text { or inhibition of } \\
\text { irreversible } \\
\text { attachment of the } \\
\text { biofilm-forming } \\
\text { bacteria that prevent } \\
\text { biofilm formation }\end{array}$ & $\begin{array}{c}\text { P. aeruginosa PAO1/ATCC } 27853, \\
\text { MRSA ATCC } 43300\end{array}$ & $\begin{array}{l}\text { Onbas T, } \\
2019\end{array}$ \\
\hline Papaya & $\begin{array}{l}\text { Lp } \\
\text { ST16Pa }\end{array}$ & Bacteriocin ST16Pa & $\begin{array}{c}\text { Cell lysis and } \\
\text { enzymes leakage }\end{array}$ & $\begin{array}{c}\text { L. innocua, Latilactobacillus sakei, } \\
\text { Enterococcus faecalis }\end{array}$ & $\begin{array}{c}\text { Sabo SS, } \\
\text { 2019; } \\
\text { Todorov SV, } \\
2011\end{array}$ \\
\hline Cabbage pickles & $\begin{array}{l}\text { Lp NTU } \\
102\end{array}$ & $\mathrm{LPB}_{102}{ }^{7}$ & $\begin{array}{l}\text { Suppression of } \\
\text { resistance } \\
\text { nodulation cell } \\
\text { division (RND)-type } \\
\text { efflux transporter } \\
\text { genes }\end{array}$ & $\begin{array}{c}\text { V. parahaemolyticus, Cronobacter } \\
\text { sakazakii }\end{array}$ & Lin T, 2019 \\
\hline Yoghurt & Lp DM 69 & $\begin{array}{c}\text { Protein (MW } 12.0 \\
\text { kDa) } \\
\text { Proteinaceous } \\
\text { compound }\end{array}$ & $\begin{array}{l}\text { Inhibited adhesion } \\
\text { and invasion of } S \text {. } \\
\text { enterica into colon } \\
\text { cells }\end{array}$ & $\begin{array}{l}\text { S. enterica subsp. enterica ATCC } \\
35640 \\
\text { B. cereus ATCC 10702, S. aureus } \\
\text { subsp. aureus ATCC 29213, S. } \\
\text { aureus MTCC 902, P. aeruginosa } \\
\text { MTCC 741, Klebsiella pneumonia } \\
\text { MTCC } 109\end{array}$ & $\begin{array}{l}\text { Mohanty } \\
\text { DP, } 2019 \\
\text { Mohanty } \\
\text { DP, } 2016\end{array}$ \\
\hline
\end{tabular}


Table 1. Cont.

\begin{tabular}{|c|c|c|c|c|c|}
\hline Isolation Niche & $\begin{array}{l}\text { Strain } \\
\text { Name }\end{array}$ & $\begin{array}{c}\text { Type of } \\
\text { Antimicrobial }\end{array}$ & $\begin{array}{c}\text { Investigated Action } \\
\text { Mechanism }\end{array}$ & $\begin{array}{l}\text { Strong Antimicrobial Activity/ } \\
\text { Inhibited Bacterial Species }\end{array}$ & Reference \\
\hline Fish & Lp LPL-1 & Bacteriocin LPL-1 & $\begin{array}{c}\text { Increases membrane } \\
\text { permeability, } \\
\text { induces collapse of } \\
\text { proton motive force, } \\
\text { inhibits expression } \\
\text { of genes related to } \\
\text { virulence factors, } \\
\text { biofilm formation } \\
\text { factors, and RNA } \\
\text { polymerase sigma } \\
\text { factor }\end{array}$ & L. monocytogenes 54002 & $\begin{array}{l}\text { Wang Y, } \\
2019 \text { and } \\
2018\end{array}$ \\
\hline Ricotta cheese & Lp L899 & EPSs & $\begin{array}{l}\text { Inhibition of biofilm } \\
\text { and efflux pumps }\end{array}$ & E. coli ATCC 35218 & $\begin{array}{l}\text { Mahdhi A, } \\
\quad 2018\end{array}$ \\
\hline $\begin{array}{l}\text { Salted and } \\
\text { fermented } \\
\text { shrimp }\end{array}$ & Lp FB003 & CFS & n.i. & $\begin{array}{l}\text { L. monocytogenes, S. aureus, } \\
\text { Salmonella enterica serotype } \\
\text { Choleraesuis, V. parahaemolyticus }\end{array}$ & Le B, 2018 \\
\hline Shrimp gut & $\begin{array}{c}\text { Lp } \\
\text { SGLAB01 }\end{array}$ & CFS & $\begin{array}{l}\text { Modulation of the } \\
\text { host } \text { proPO }^{8} \text { system }\end{array}$ & $\begin{array}{c}\text { Aerococcus viridans, Vibrio harveyi, } \\
\text { S. aureus, Bacillus megaterium, } \\
\text { Bacillus subtilis, E. coli, } V . \\
\text { parahaemolyticus }\end{array}$ & $\begin{array}{c}\text { Chomwong } \\
\text { S, } 2018\end{array}$ \\
\hline Yak cheese & LP SLG1 & Plantaricin SLG1 & $\begin{array}{l}\text { Bactericidal mode of } \\
\text { action, it damages } \\
\text { cell membrane and } \\
\text { induces the release } \\
\text { of cytoplasmic } \\
\text { components }\end{array}$ & $\begin{array}{c}\text { B. subtilis, B. cereus, B. megaterium, } \\
\text { M. luteus, Brochothrix } \\
\text { thermosphacta, C. butyricum, S. } \\
\text { aureus, L. innocua, L. } \\
\text { monocytogenes, E. coli, } P \text {. } \\
\text { aeruginosa, Enterobacter cloacae and } \\
\text { Salmonella paratyphi } b\end{array}$ & Pei J, 2018 \\
\hline $\begin{array}{l}\text { Fermented chinese } \\
\text { milk }\end{array}$ & Lp J23 & $\begin{array}{l}\text { Bacteriocin } \\
\text { Lac-B23 }\end{array}$ & n.i. & L. monocytogenes & $\begin{array}{l}\text { Zhang J, } \\
2018\end{array}$ \\
\hline $\begin{array}{l}\text { Dong-nationality } \\
\text { kipper }\end{array}$ & $\begin{array}{c}\text { Lp } \\
\text { GZ1-27 }\end{array}$ & Plantaricin GZ1-27 & $\begin{array}{c}\text { Increased cell } \\
\text { membrane } \\
\text { permeability, } \\
\text { triggered K+ leakage } \\
\text { and pore formation, } \\
\text { damaged cell } \\
\text { membrane integrity, } \\
\text { reduced expression } \\
\text { of genes related to } \\
\text { cytotoxin } \\
\text { production, } \\
\text { peptidoglycan } \\
\text { synthesis, and cell } \\
\text { division }\end{array}$ & B. cereus & Du H, 2018 \\
\hline Sai krok e-san mu & Lp SKI19 & BLIS & n.i. & $\begin{array}{c}\text { L. monocytogenes DMST 17303, B. } \\
\text { cereus DMST 5040, C. perfringens } \\
\text { DMST 1663, S. aureus DMST 8840, } \\
\text { E. coli DMST 4212, S. Typhimurium } \\
\text { DMST 15674, S. enteritidis DMST } \\
15676\end{array}$ & $\begin{array}{l}\text { Botthoulath } \\
\text { V, } 2018\end{array}$ \\
\hline Cabbage & Lp DL3 & Plantaricin DL3 & $\begin{array}{l}\text { Disruption of } \\
\text { pathogen cell wall } \\
\text { and leakage of } \\
\text { proteins }\end{array}$ & $\begin{array}{c}\text { P. aeruginosa, L. monocytogenes, } \\
\text { Shewanella putrefaciens, } \\
\text { Psychrobacter sp., S. aureus, B. } \\
\text { cereus, Bacillus licheniformis, P. } \\
\text { fuorescens }\end{array}$ & Lv X, 2018 \\
\hline
\end{tabular}


Table 1. Cont.

\begin{tabular}{|c|c|c|c|c|c|}
\hline Isolation Niche & $\begin{array}{l}\text { Strain } \\
\text { Name }\end{array}$ & $\begin{array}{c}\text { Type of } \\
\text { Antimicrobial }\end{array}$ & $\begin{array}{l}\text { Investigated Action } \\
\text { Mechanism }\end{array}$ & $\begin{array}{l}\text { Strong Antimicrobial Activity/ } \\
\text { Inhibited Bacterial Species }\end{array}$ & Reference \\
\hline Olive & Lp NI326 & $\begin{array}{c}\text { Plantaricyclin A } \\
\text { (PlcA) }\end{array}$ & n.i. & $\begin{array}{c}\text { Alicyclobacillus acidoterrestris, } \\
\text { Lactococcus lactis spp., Lactobacillus } \\
\text { bulgaricus UCC, Pediococcus } \\
\text { inopinatus } 1011\end{array}$ & $\begin{array}{l}\text { Borrero J, } \\
2018\end{array}$ \\
\hline $\begin{array}{l}\text { Fermented stinky } \\
\text { bean }\end{array}$ & Lp S0/7 & Organic acids & $\begin{array}{l}\text { Lowering } \\
\text { cytoplasmic } \mathrm{pH} \text { of } \\
\text { target pathogens }\end{array}$ & $\begin{array}{c}\text { E. coli DMST4212, S. aureus } \\
\text { DMST8840, B. cereus DMST5040, } \\
\text { L. monocytogenes DMST17303 }\end{array}$ & $\begin{array}{l}\text { Saelim K, } \\
\quad 2017\end{array}$ \\
\hline Human breast milk & $\begin{array}{c}\text { Lp } \\
\text { WLPL04 }\end{array}$ & EPSs & $\begin{array}{l}\text { Inhibition of the } \\
\text { biofilm formation or } \\
\text { modification of the } \\
\text { bacterial cell surfaces }\end{array}$ & $\begin{array}{l}\text { P. aeruginosa CMCC10104, E. coli } \\
\text { O157:H7, S. Typhimurium ATCC } \\
\text { 13311, and S. aureus CMCC } 26003\end{array}$ & Liu Z, 2017 \\
\hline $\begin{array}{l}\text { Shpek, bulgarian } \\
\text { salami }\end{array}$ & Lp ST8Sh & $\begin{array}{l}\text { Bacteriocin ST8SH } \\
\text { (pediocin PA-1 } \\
\text { family) }\end{array}$ & $\begin{array}{l}\text { Pathogen's cell lysis } \\
\text { and intracellular } \\
\text { material leakage }\end{array}$ & $\begin{array}{c}\text { L. monocytogenes Scott A, } \\
\text { Enterococcus faecalis ATCC } 19433 \\
\text { S. aureus }\end{array}$ & $\begin{array}{l}\text { Todorov } \\
\text { SD, } 2016 \\
\text { and } 2017\end{array}$ \\
\hline Salami & $\begin{array}{c}\mathrm{Lp} \\
\mathrm{MBSa} 4\end{array}$ & Plantaricin W & $\begin{array}{l}\text { Bacteriostatic: } \\
\text { electrostatic } \\
\text { interactions with } \\
\text { cytoplasmic } \\
\text { membranes of } \\
\text { bacteria, binds to the } \\
\text { cell surface, but not } \\
\text { killing effect }\end{array}$ & $\begin{array}{c}\text { L. monocytogenes, S. aureus ATCC } \\
\text { 25923, Enterococcus hirae, } \\
\text { Enterococcus faecium, L. innocua, L. } \\
\text { welshimeri }\end{array}$ & $\begin{array}{l}\text { Barbosa } \\
\text { MS, } 2016\end{array}$ \\
\hline Yak yogurt & Lp Q7 & Plantaricin Q7 & 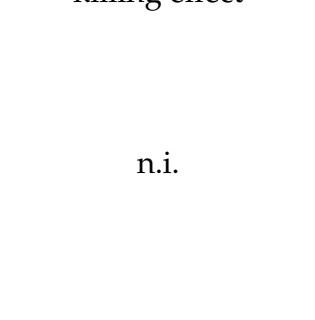 & $\begin{array}{c}\text { Pseudomonas fluorescens AS1.1802, } \\
\text { P. putida AS1.1819, P, aeruginosa } \\
\text { CICC 21636, L. monocytogenes } \\
\text { ATCC 19111, S. aureus, E. coli } \\
\text { ATCC 25922, S. flexneri ATCC } \\
\text { 12022, Shigella sonnei ATCC 25931, } \\
\text { S. enterica serovar typhimurium } \\
\text { ATCC } 14028\end{array}$ & Liu H, 2016 \\
\hline Wine & $\begin{array}{l}\text { Lp } 105 \\
\text { Lp 106, } \\
\text { Lp 107 Lp } \\
\text { 119, Lp } \\
\text { 32, Lp108 }\end{array}$ & CFS (pH acid) & n.i. & $\begin{array}{c}\text { L. monocytogenes CECT 4032, E. } \\
\text { coli O157:H7, S. Enteritidis CECT } \\
\text { 409, S. aureus R1070, R1208, S1209, } \\
\text { and S1220 }\end{array}$ & $\begin{array}{l}\text { Arena MP, } \\
2016\end{array}$ \\
\hline $\begin{array}{l}\text { Suan-Tsai: chinese } \\
\text { fermented cabbage }\end{array}$ & Lp JLA-9 & Plantaricin JLA-9 & $\begin{array}{l}\text { Inhibited growth by } \\
\text { preventing the } \\
\text { establishment of } \\
\text { oxidative } \\
\text { metabolism and } \\
\text { disrupting } \\
\text { membrane integrity } \\
\text { in germinating } \\
\text { spores of } B \text {. cereus }\end{array}$ & $\begin{array}{c}\text { B. cereus, B. pumilus, B. megaterium, } \\
\text { Bacillus coagulans, B. subtilis, } \\
\text { Geobacillus stearothermophilus, } \\
\text { Alicyclobacillus acidoterrestris, } \\
\text { Paenibacillus polymyxa, C. difficile, } \\
\text { C. perfringens, C. sporogenes, S. } \\
\text { aureus, M. luteus, P. fluorescens, S. } \\
\text { marcescens, E. coli, S. enteritidis, S. } \\
\text { typhimurium, S. paratyphi A, S. } \\
\text { paratyphi B, S. flexneri, Proteus } \\
\text { mirabilis }\end{array}$ & $\begin{array}{l}\text { Zhao S, } \\
2016\end{array}$ \\
\hline Dosa batter & Lp K25 & Plantaricin K25 & $\begin{array}{c}\text { Membrane surface } \\
\text { disruption of the B. } \\
\text { cereus cells, leakage } \\
\text { and release of } \\
\text { cellular contents } \\
\mathrm{K}^{+} \text {ion efflux and } \\
\text { pore-forming on } \\
\text { membrane of M. } \\
\text { luteus and E. coli } \\
\text { cells }\end{array}$ & $\begin{array}{l}\text { M. luteus, S. aureus, E. coli } \\
\text { (urogenic), P. aeruginosa, S. typhi, } \\
\text { Vibrio sp., E. cloacae, E. faecium }\end{array}$ & $\begin{array}{l}\text { Kumar V, } \\
2016\end{array}$ \\
\hline
\end{tabular}


Table 1. Cont.

\begin{tabular}{|c|c|c|c|c|c|}
\hline Isolation Niche & $\begin{array}{l}\text { Strain } \\
\text { Name }\end{array}$ & $\begin{array}{c}\text { Type of } \\
\text { Antimicrobial }\end{array}$ & $\begin{array}{l}\text { Investigated Action } \\
\text { Mechanism }\end{array}$ & $\begin{array}{l}\text { Strong Antimicrobial Activity/ } \\
\text { Inhibited Bacterial Species }\end{array}$ & Reference \\
\hline Meat & Lp KL-1 & Plantaricin KL-1Y & $\begin{array}{c}\text { Bactericidal activity } \\
\text { without cell lysis }\end{array}$ & $\begin{array}{c}\text { B. cereus JCM 2152T, S. enterica } \\
\text { serovar Enteritidis DMST 17368, P. } \\
\text { aeruginosa ATCC 15442, P. } \\
\text { aeruginosa ATCC 9027, E. coli } \\
\text { O157:H7, E. coli ATCC 8739, B. } \\
\text { coagulans JCM 2257T, L. innocua } \\
\text { ATCC 33090T, S. aureus TISTR } 118\end{array}$ & $\begin{array}{c}\text { Rumjuankiat } \\
\text { K, } 2015\end{array}$ \\
\hline Indonesian beef & $\begin{array}{l}\mathrm{Lp} \\
\text { IIA-IA5 }\end{array}$ & $\begin{array}{l}\text { Plantaricin } \\
\text { IIA-1A5 }\end{array}$ & $\begin{array}{l}\text { Loss of membrane } \\
\text { integrity, release of } \\
\text { proteinaceous and } \\
\text { genetic materials }\end{array}$ & $\begin{array}{l}\text { S. aureus, Enteropathogenic E. coli } \\
\text { K1, Shigella A33, Salmonella } 38\end{array}$ & $\begin{array}{l}\text { Sihombing } \\
\text { DE, } 2015 \\
\text { Arief II, } \\
2015\end{array}$ \\
\hline Kefir grains & Lp YW32 & EPSs & $\begin{array}{l}\text { Concentration- } \\
\text { dependent inhibitory } \\
\text { effect on the biofilms' } \\
\text { formation }\end{array}$ & $\begin{array}{l}\text { E. coli O157, S. flexneri CMCC, S. } \\
\text { aureus AC1, S. typhimurium S50333 }\end{array}$ & $\begin{array}{l}\text { Wang J, } \\
2015\end{array}$ \\
\hline Sheep-milk cheese & Lp U4 & Plantaricin LpU4 & $\begin{array}{l}\text { Bacteriostatic mode } \\
\text { of action and an } \\
\text { enhanced activity at } \\
\text { acidic pHs }\end{array}$ & E. faecalis JH2-2, MRSA & $\begin{array}{l}\text { Milioni C, } \\
2015\end{array}$ \\
\hline Koshu vineyard & Lp 510 & Plantaricin $\mathrm{Y}$ & n.i. & L. monocytogenes BCRC 14845 & $\begin{array}{c}\text { Chen Y, } \\
2014\end{array}$ \\
\hline Vaginal microbiota & $\begin{array}{c}\text { Lp } \\
\text { CMUL140 }\end{array}$ & $\begin{array}{l}\text { bacteriocin-like } \\
\text { inhibitory } \\
\text { substances (BLIS) }\end{array}$ & n.i. & $\begin{array}{c}\text { G. vaginalis CIP7074T, E. coli } \\
\text { CIP103982, S. aureus ATCC } 33862\end{array}$ & $\begin{array}{l}\text { Al Kassaa I, } \\
2014\end{array}$ \\
\hline $\begin{array}{l}\text { 'Kanjika' } \\
\text { (ayurvedic } \\
\text { rice-based } \\
\text { fermented } \\
\text { product) }\end{array}$ & $\begin{array}{l}\text { Lp CFR } \\
2194\end{array}$ & Biosurfactants & $\begin{array}{l}\text { Cell membrane lysis; } \\
\text { antiadhesive activity }\end{array}$ & $\begin{array}{c}\text { E. coli ATCC 31705, E. coli MTCC } \\
\text { 108, S. aureus F 722, Y. } \\
\text { enterocolitica MTCC } 859\end{array}$ & $\begin{array}{l}\text { Madhu AN, } \\
2014\end{array}$ \\
\hline mustard & Lp ZJ5 & Plantaricin ZJ5 & n.i. & $\begin{array}{l}\text { S. aureus CGMCC } 1.128, \text { L. } \\
\text { plantarum, L. monocytogenes, B. } \\
\text { subtilis, M. luteus, P. putida, E. coli, } \\
\text { Shigella dysenteriae }\end{array}$ & $\begin{array}{l}\text { Song DF, } \\
2014\end{array}$ \\
\hline Breast milk & Lp R315 & EPSs & n.i. & $\begin{array}{l}\text { L. monocytogenes CMCC54007, S. } \\
\text { aureus CGMCC26003, B. cereus } \\
\text { ATCC 14579, S. typhimurium } \\
\text { ATCC 1331, C. sakazakii ATCC } \\
\text { 29544, S. sonnei ATCC } 25931\end{array}$ & Li S, 2014 \\
\hline Fresh milk & Lp ZJ008 & Plantaricin ZJ008 & $\begin{array}{l}\text { Bactericidal mode of } \\
\text { action, pores } \\
\text { formation in the } \\
\text { surface of cell } \\
\text { membrane but not } \\
\text { cell lysis }\end{array}$ & $\begin{array}{l}\text { S. citreus LC5, S. carnosus LTH1502 } \\
\text { MRSA D48, S. epidermidis Z80, } \\
\text { Micrococcus luteus 10209, L. } \\
\text { monocytogenes LM1, E. coli DH5 } \alpha, \\
\text { S. flexneri DSM4782 }\end{array}$ & Zhu X, 2014 \\
\hline Dairy & $\begin{array}{c}\mathrm{Lp} \\
\text { HKN01 }\end{array}$ & bacteriocin-like & n.i. & $\begin{array}{c}\text { E. coli (PTCC 1338), S. } \\
\text { Typhimurium (ATCC 13311), K. } \\
\text { pneumoniae (PTCC 1290) }\end{array}$ & $\begin{array}{l}\text { Sharafi H, } \\
2013\end{array}$ \\
\hline Vegetable & Lp 163 & Plantaricin 163 & n.i. & $\begin{array}{c}\text { S. aureus, B. cereus, } L . \\
\text { monocytogenes, B. pumilus, E. coli, } \\
\text { P. aeruginosa, and P. fluorescens, } M \text {. } \\
\text { luteus, L. thermophilus, } L . \\
\text { rhamnosus }\end{array}$ & Hu M, 2013 \\
\hline
\end{tabular}


Table 1. Cont.

\begin{tabular}{|c|c|c|c|c|c|}
\hline Isolation Niche & $\begin{array}{l}\text { Strain } \\
\text { Name }\end{array}$ & $\begin{array}{c}\text { Type of } \\
\text { Antimicrobial }\end{array}$ & $\begin{array}{l}\text { Investigated Action } \\
\text { Mechanism }\end{array}$ & $\begin{array}{l}\text { Strong Antimicrobial Activity/ } \\
\text { Inhibited Bacterial Species }\end{array}$ & Reference \\
\hline Meat & Lp BM-1 & bacteriocin BM-1 & $\begin{array}{l}\text { Bactericidal mode of } \\
\text { action without cell } \\
\text { membrane lysis }\end{array}$ & $\begin{array}{c}\text { L. monocytogenes ATCC 54003, E. } \\
\text { facealis AS 1.2984, L. pentosus } \\
\text { ATCC 8041, L. plantarum F1, S. } \\
\text { aureus ATCC6535, E. coli } \\
\text { CDC85933, S. dysenteriae CMCC } \\
51105 \text { and S. enteritidis CMCC } \\
\text { 50041 }\end{array}$ & $\begin{array}{l}\text { Zhang H, } \\
2013\end{array}$ \\
\hline- & $\begin{array}{l}\text { Lp ATCC } \\
10241\end{array}$ & CFS & $\begin{array}{c}\text { Prevents } P \text {. } \\
\text { aeruginosa } \\
\text { quorum-sensing; } \\
\text { inhibition of biofilm } \\
\text { formation; inhibited } \\
\text { production of } \\
\text { virulence factors } \\
\text { (elastase, pyocyanin, } \\
\text { rhamnolipids) }\end{array}$ & P. aeruginosa & $\begin{array}{c}\text { Ramos AN, } \\
2012\end{array}$ \\
\hline Papaya & $\begin{array}{l}\mathrm{Lp} \\
\text { ST16Pa }\end{array}$ & bacteriocin ST16Pa & $\begin{array}{l}\text { Bactericidal mode of } \\
\text { action, cell lysis and } \\
\text { enzyme-leakage }\end{array}$ & $\begin{array}{l}\text { L. innocua 2030C, L. sakei ATCC } \\
\text { 15521, E. faecalis ATCC } 19433\end{array}$ & $\begin{array}{l}\text { Todorov, } \\
2011\end{array}$ \\
\hline $\begin{array}{l}\text { Thai dyspeptic } \\
\text { patient }\end{array}$ & Lp B7 & CFS (pH acid) & $\begin{array}{l}\text { Inhibition of the } \\
\text { pathogen's urease } \\
\text { activity and viability }\end{array}$ & Helicobacter pylori ATCC 43504 & $\begin{array}{l}\text { Sunanliganon } \\
\quad \text { C, } 2012\end{array}$ \\
\hline Koumiss & Lp LB-B1 & pediocin LB-B1 & n.i. & $\begin{array}{c}\text { L. monocytogenes, Lactobacillus spp, } \\
\text { Streptococcus spp, Enterococcus spp, } \\
\text { Pediococcus spp, E. coli }\end{array}$ & Xie Y, 2011 \\
\hline
\end{tabular}

${ }^{1}$ Lp: L. plantarum; ${ }^{2}$ n.i., not investigated by the authors; ${ }^{3}$ CFS: cell-free supernatants; ${ }^{4}$ EPSs: Exopolysaccharides; ${ }^{5}$ L-PLA: L-phenyl lactic acid; ${ }^{6}$ SCFA: short-chain fatty acids; ${ }^{7}$ LPB102: 2-(2-1 mino-1-hydroxyethoxy) ethyl 2-methylpropanoate; ${ }^{8}$ PO: phenoloxidase.

\section{Nature and Mechanisms of L. plantarum Antimicrobials}

Two modalities are basically involved in the antimicrobial action: (i) bacteriostatic, which means that the antimicrobial agent prevents the growth of target microbe, and (ii) bactericidal, which means that the agent kills the target cell. However, the exact microbiological bactericidal or bacteriostatic setting of bacterial-related agents may be influenced by growth conditions, bacterial density, duration of the test used, and measure of reduction in bacterial numbers [35].

The antimicrobials produced by lactobacilli are quite diverse and fall within two main chemical categories, proteinaceous and non-proteinaceous substances. Data reported in Tables 1 and 2 show that the antimicrobial activity of L. plantarum is mainly exerted by bacteriocins ( $\sim 60 \%$ of the reported strains) or partially characterised proteinaceous compounds, followed by organic acids or acidic conditions (i.e., acid CFS [25]), and biosurfactants (BS) such as glycoproteins and EPS.

\subsection{Bacteriocins}

Bacteriocins are a heterogeneous group of ribosomally synthesised, gene-encoded peptides with specific antimicrobial activity towards a spectrum of target microbes, which can be narrow or broad depending on the producing strain [23]. The bacteriocins produced by L. plantarum spp. are referred to as plantaricins; generally, they are small, heat-stable, frequently very potent, being active at nanomolar concentrations, and exert their killing effect mostly through membrane permeabilization, through pore formation and subsequent leakage of cytoplasmic compounds. For their high antimicrobial versatility, they have been considered for use as bio-preservatives, antibiotic alternatives, health-promoting gut modulators and animal growth promoters [36]. 
Table 2. Probiotic L. plantarum strains with documented in vitro antiviral activity.

\begin{tabular}{|c|c|c|c|c|c|}
\hline Isolation Niche & Strain Name & Type of Antiviral & Mechanism & $\begin{array}{c}\text { Strong Antiviral } \\
\text { Activity/ } \\
\text { Virus Inhibited }\end{array}$ & Reference \\
\hline Kimchi & Lp ${ }^{1}$ NIBR97 & Plantaricin 3 and 5 & $\begin{array}{l}\text { Lysis through } \\
\text { envelope collapse }\end{array}$ & $\begin{array}{l}\text { HIV-based } \\
\text { lentivirus, Influenza } \\
\text { virus A/H3N2 }\end{array}$ & Kim SW, 2020 \\
\hline- & Lp ATCC LP299v & Metabolites & n.i. & Rotavirus Wa & Bernal SC, 2020 \\
\hline Animals faeces & Lp AA09a & $\mathrm{CFS}^{2}$ & n.i. & $\begin{array}{l}\text { Echovirus } 7 \text { (E7), } \\
\text { E19 }\end{array}$ & Sunmola AA, 2019 \\
\hline Piglet faeces & Lp-1s & CFS & n.i. & $\begin{array}{l}\text { Transmissible } \\
\text { gastroenteritis virus } \\
(\text { TGEV) }\end{array}$ & Wang K, 2019 \\
\hline Kimchi & Lp LRCC5310 & $\mathrm{EPSs}^{3}$ & n.i. & $\begin{array}{l}\text { Human rotavirus } \\
(H R V)\end{array}$ & Kim K, 2018 \\
\hline Wine & $\begin{array}{l}\text { Lp UNIFG30 Lp } \\
\text { UNIFG121 }\end{array}$ & CFS & n.i. & $\begin{array}{l}\text { Enterovirus } \\
\text { Coxsackievirus B4 }\end{array}$ & Arena MP, 2018 \\
\hline Pig faeces & Lp 22F, 25F, 31F & CFS & n.i. & $\begin{array}{l}\text { Porcine epidemic } \\
\text { diarrhoea virus } \\
(P E D V)\end{array}$ & $\begin{array}{l}\text { Sirichokchatchawan } \\
\text { W, } 2018\end{array}$ \\
\hline Kimchi & Lp LBP-K10 & Cyclic dipeptides & $\begin{array}{l}\text { Conformational } \\
\text { structures of cyclic } \\
\text { dipeptides } \\
\text { influence genes } \\
\text { that cause viral } \\
\text { infections }\end{array}$ & $\begin{array}{l}\text { Influenza A (H3N2) } \\
\text { virus }\end{array}$ & Kwak MK, 2013 \\
\hline
\end{tabular}

${ }^{1}$ Lp: L. plantarum ${ }^{2}$ CFS: cell-free supernatants; ${ }^{3}$ EPSs: exopolysaccharides.

As observed for other bacteriocins, the production of plantaricins is regulated through a quorum-sensing based network and seems to be switched on by specific signals that characterise the natural niche of the strain [37]. Stress conditions and co-culture with other specific inducing bacteria usually enhance plantaricin gene expression [38-40]. Likewise, the accumulation of signalling molecules, such as the PlnA peptide, outside the bacterial cells, can modulate bacteriocin production [40]. Intriguingly, transcriptomic and genomic studies in the reference strain L. plantarum WCFS1 pointed out that plantaricins synthesis may be triggered in vivo, during transit along the gut [41,42], thereby providing competitive advantages over other intestinal resident microbes, contributing to microbiota balance and possibly playing a role in the molecular interplay with the host immune system $[43,44]$.

Like bacteriocins, even plantaricins can be roughly divided into two classes, which, in turn, include subclasses: Class I, containing post-translationally modified peptides, and Class II, containing predominantly unmodified peptides. Being amphiphilic, plantaricins interact electrostatically with the negatively charged bacterial cell surface (mainly constituted by phospholipids and lipopolysaccharides) by their positively charged group (cationic plantaricins) [45], while their hydrophobic portion passes through the membrane lipid bilayer of target bacteria. After internalisation, the peptides aggregate to form polymers or complexes, which create holes in the cell wall and the membrane, causing a change in permeability with consequent leakage and depletion of intracellular compounds (e.g., genetic and proteinaceous material), eventually leading to cell membrane lysis [46-49].

A few studies reported in Tables 1 and 2 investigated the mechanism of action of plantaricins; among them, Kim and co-workers showed that plantaricins 3 and 5, from $L$. plantarum NIBR97, inhibited S. Enteritidis growth, causing its cellular lysis by damaging the membrane via pore formation [48]. Synthetic plantaricins 3 and 5 were further investigated for antiviral activity against GFP-labelled lentiviruses and, interestingly, scanning electron micrography (SEM) revealed that plantaricin 3 caused lentiviral lysis in human host cells through the collapse of their envelopes, while plantaricin 5 did not, implying two different antiviral mechanisms [50]. Tenea and co-workers investigated the mechanism by which 
Gt2 peptides and Cys5-4 peptides, from L. plantarum UTNGt2 and UTNCys5-4, respectively, target Gram-negative bacteria (Table 1). Gt2 and Cys5-4 peptides comprise, in turn, two or more post-translationally modified peptides forming one aggregate forming one functional inhibitory unit, which altered the cellular membrane permeability of E. coli and Salmonella, causing the leakage of cytoplasmic contents, followed by cellular death [50,51]. In a later study, the same authors investigated deeply the changes in Salmonella cells treated with Gt2 and Cys5-4 extracts, highlighting the occurrence of direct interaction between Salmonella genomic DNA and the peptides [46]. Such interaction has also been observed for antibacterial compounds from other species and was suggested to concur to the antimicrobial effects, i.e., by inducing DNA damages and genomic instability [52].

Data collected so far suggest that the action mode for plantaricins is usually bactericidal, through the induction of ion-selective pores in the target cell membrane, which causes the dissipation of intracellular ATP and depletion of the proton motive force, leakage of intracellular substances, followed by cell death. However, bacteriostatic effects have been reported for plantaricin W [53] and plantaricin LpU4 [54], as well as for other plantaricins previously studied $[55,56]$. In these cases, it has been suggested that plantaricin binds to target cell surface without reaching the specific receptors needed to achieve the killing effect [53]. In addition, certain L. plantarum strains produce more than one bacteriocin, either acting individually, e.g., bacteriocins F1 and F2 which exhibit different levels of efficacy against Staphylococcus aureus [57], or whose combination/synergic action results in higher antibacterial efficacy, e.g., plantaricin KL-1Y [58]. It is also worth mentioning that some plantaricins, such as KL-1Y [58], ZJ008 [59] and BM-1 [60], exert a bactericidal action without apparent cell lysis, whereas some, e.g., BM-1, can inhibit Gram-negative bacteria growth by bacteriostatic action, by influencing metabolic pathways and affecting the cell wall structure, eventually causing its collapse [61].

In addition to plantaricins, other L. plantarum proteinaceous compounds have been ascribed antibacterial activity. In most studies, such antimicrobials are generically referred to as bacteriocin-like peptides. For instance, the extracellular anti-staphylococcal protein fractions produced by a strain isolated from meat were recently identified as a couple of enzymes (i.e., transglycosylase and glyceraldehyde-3-phosphate dehydrogenase (GADPH)), which inhibit $S$. aureus growth through different mechanisms [62]. Extracellular transglycosylase binds to $S$. aureus peptidoglycan, thereby degrading the cell wall until cell lysis occurs; once the membrane has been damaged by transglycosylase, GADPH enters the cell and up-regulates $S$. aureus autolysis genes [62].

Considering the key role of the membrane surface charge and fluidity in the action mode of bacteriocins, it is easy to guess that the manipulation of these two bacterial properties may render the bacteriocins ineffective, resulting in bacteriocin resistance [63,64], or, on the other hand, in higher efficacy, which might be achieved for instance by bioengineering [65]. That being said, this represents an important mechanism of bacterial adaptation [66] that deserves to be studied and treated in depth separately, as it goes beyond the focus of this review.

\subsection{Organic Acids}

L. plantarum antimicrobial activity also often depends on the production and release of different types of organic acids (primarily, lactic and acetic acids, to follow tartaric, citric, malic, oxalic, and succinic acid) and on the associated $\mathrm{pH}$ lowering of the surrounding environment. Both factors concur to hinder the survival of acid-sensitive microorganisms [67]. Even short-chain fatty acids (SCFAs), e.g., butyric, propionic and valeric acids, and their modified derivatives have been ascribed antibacterial activity.

Since the growth of important food-spoilage and food-poisoning microorganisms is inhibited at low $\mathrm{pH}(<4)$, L. plantarum, which is one of the lactobacilli with the highest lactic acid production rate $[25,68]$, can be added to many fermented foods as a natural preservative $[69,70]$. LAB, including L. plantarum, may be homofermentative or heterofermentative depending on the pathway used for glucose fermentation. Homofermentative 
bacteria produced more lactic acid through glycolysis compared to heterofermentative bacteria, which ferment glucose via the 6-phosphogluconate/phosphoketolase pathway [71]. Because different strains produce different types, amounts and combinations of organic acids, the resulting overall inhibitory actions are quite variable. There is much here to indicate that the antimicrobial mechanism resulting from $\mathrm{pH}$ acidification is species- and strain-specific $[70,72]$. The hydrophobic, undissociated form of the acid permeates the cell membrane and dissociates inside the target cell as a consequence of the intracellular neutral $\mathrm{pH}$ conditions, thereby acidifying the cytoplasm. The acid $\mathrm{pH}$ and the neutralisation of the electrochemical proton gradient stops various $\mathrm{pH}$-dependent transport mechanisms causing bacteriostasis and eventually cell death [73,74]. The $\mathrm{pH}$ variation of the cytoplasmic environment depends on the specific $\mathrm{pKa}$ values of the organic acids produced by the L. plantarum strain, which explains the variability of their antimicrobial action [68]. Furthermore, by their chelating properties, organic acids can capture essential growth elements, such as iron [75].

Some modified acids have also been ascribed antibacterial activity. A derivative of propionic acid, i.e. 2-(2-1 mino-1-hydroxyethoxy) ethyl 2-methylpropanoate (LPB 102), was found to be the antimicrobial agent produced by L. plantarum NTU 102, with inhibitory action against Vibrio parahaemolyticus, a bacterium that is frequently associated with foodborne outbreaks of disease [76]. The authors attributed the inhibitory effects of LPB 102 to the suppression of specific $V$. parahaemolyticus genes that underlie its intrinsic resistance to various antimicrobial agents [77].

3-Phenyl lactic acid (PLA), a metabolite produced by some LAB from phenylalanine catabolism [78], is quite a new type of powerful and broad-spectrum antimicrobial compound that is active against both bacteria and fungi [79]. For its capacity to contrast food spoilage microorganisms, it is considered a valuable natural food preservative. Therefore, PLA biosynthesis, and strategies to increase its yield in starter LAB, have attracted much research effort $[78,80]$. PLA occurs in two enantiomers, L-PLA and D-PLA, whose difference in antibacterial capacity is still debated [81,82]. In a few pathogenic species, among those that are sensitive to PLA, this compound has been demonstrated to function by targeting the bacterial membrane [83,84], i.e., affecting its charge distribution and hydrophobic properties [85]. In Listeria monocytogenes, a mixture of the two isomers, obtained from a fermented vegetable L. plantarum isolate, was found to disrupt the cell membrane, and induce pore formation and leakage of intracellular material by interacting with cell membrane proteins [86]. Such mechanism of action has been recently confirmed also for the anti-Salmonella activity of PLA chemically characterised and purified from an infant faeces-isolated L. plantarum strain [26]. Intriguingly, the authors observed that, besides destroying the cell membrane, the purified compound was able to intercalate genomic DNA, suggesting a further mode of action for this molecule [26].

\subsection{Biosurfactants}

BS are amphipathic molecules with a hydrophilic head moiety and a hydrophobic tail, whose balance provides their surface activity [87]. In lactobacilli, BS are either extracellularly secreted or cell-bound components, and have been identified as chemically different molecules, including lipopeptides [88], glycopeptides [89], glycoproteins [90,91], glycolipids [92], phospholipids and polysaccharides [93]. Antimicrobials with BS properties usually exert a bacteriostatic action, and typically destabilise membranes and affect cell adherence, a key pathogenic feature, as it enhances colonisation ability by potential pathogens on both biotic (e.g., host mucosae) and abiotic surfaces (e.g., food, surgical instrument, implanted medical devices). BS from lactobacilli have been shown to inhibit foodborne pathogens $[90,91,94]$, to possess antibiofilm [91,94] and antiadhesive [91,94] properties against fastidious or pathogenic microbes, as well as antiviral and anti-cancer activities [91], hence supporting their potential application in various fields, e.g., to contrast infections, particularly hospital-acquired infections [87,95], or to reduce microbial colonisation on food surfaces $[96,97]$. 
A few studies have characterised the action mechanism of proteinaceous BS from L. plantarum spp. Crude BS extracted from an L. plantarum cheese isolate were found to counteract, dose-dependently, biofilm formation of $S$. aureus, apparently by affecting the expressions of biofilm-related genes and by interfering with quorum-sensing signalling [94]. The BS produced by L. plantarum 60FHE was structurally characterised and identified as a mixture of glycoproteins, which exert antimicrobial activity against some foodborne pathogens (Table 1), possibly through penetration into the cell and by rupturing the membrane, leading to cell lysis [91]. Interestingly, the biosurfactant produced from this strain was also shown to be a potential anti-cancer agent [91].

Some L. plantarum exopolysaccharides (EPS) have BS-related antimicrobial properties. EPS, i.e., hydrophilic extracellular high-molecular-mass polymers, are produced by different $L A B$ and exhibit high structural diversity in terms of sugar compositions, type of bonds between the repeating units, chain length, branching, and non-sugar modifications [87]. In L. plantarum the ability to synthesise EPS is a strain-specific trait and requires the presence of specific gene clusters encoding for regulatory factors and enzymes that enable biosynthesis and assembly of the sugar monomers and secretion of the polysaccharide [98]. In addition to the antimicrobial [99] and antibiofilm activities [100-104], L. plantarum EPS have been ascribed other properties that may impact the interaction with the host and can account for the health benefits provided by probiotic lactobacilli, such as immune-stimulating [98,105,106], antioxidant [107] and anti-cancer activities [108,109].

Generally, EPS from LAB, including L. plantarum, exert their antibacterial activity by interfering with the adhesion to surfaces and with cell adhesion/recognition mechanisms, thereby contrasting the formation of biofilm $[99,103]$. Biofilms are surface-associated, complex microbial communities, embedded in a self-synthesised polymeric matrix. These multicellular, three-dimensional structures develop thanks to inter-cellular signalling and through modulation of cell adhesion properties, and can confer to microbes a greater resistance to antibiotics [110]. Song and co-workers reported that EPS produced by $L$. plantarum 12 exert antibiofilm activity against Shigella flexneri, a foodborne enteric pathogen that can induce bacillary dysentery [101]. The authors found that the active form of its EPS (i. e., L-EPS) decreased polysaccharide production in the extracellular polymeric matrix of S. flexneri only by direct contact with the pathogen and without affecting its growth. L-EPS were hypothesised to disturb the signalling involved in biofilm formation and to interfere with the extracellular polymeric structures of the pathogen, which is crucial for maintaining the integrity of its biofilm [101]. Within biofilms, which can colonise the surfaces of medical equipment or food, microbial cells gain a greater resistance to disinfectants and conventional drugs, thus representing a serious global health concern [110]. Interestingly, EPS from a cheese-isolated L. plantarum strain were found both to inhibit E. coli biofilm formation and to reduce the activity of efflux pumps implicated in drug resistance [100]. The authors ascribed the antibiofilm effect to a decreased production of indole, i.e., a metabolite putatively involved in virulence and in the quorum-sensing systems sustaining biofilm development, and to a reduction of cell surface hydrophobicity, as observed in EPS-treated E. coli cells [100].

Figure 3 sums up the different chemical nature of the principal antimicrobial agents produced by L. plantarum strains, and the suggested mechanisms underlying their antimicrobial effect.

What we are looking at reinforces the hypothesis that the antimicrobial action of a probiotic such as L. plantarum may not be due to a single molecule but to the synergic action of several molecules produced by the strain and released into the environment (i.e., growth media, food matrix or gut, according to application and niche of the strain). This is further supported by the observation that in most of the works on the isolation of the antimicrobial agents, CFS show a wider antimicrobial inhibition spectrum compared to the isolated antimicrobial agents $[40,48,76,111]$. The question is whether antimicrobial action of the isolated compound has been tested, or not, on all target pathogens used to test also the corresponding CFS. Namely, in most published papers, the antibacterial activity of CFS 
is usually tested on a broad spectrum of pathogenic bacteria, while the single CFS-derived antimicrobial compound is assayed on a single target. This can be a choice dictated by many reasons and does not necessarily mean that the isolated compound is active only against that specific target pathogen (i.e., the ones reported in Table 1). Then, perhaps, in view of applications in the food industry and human medicine, as bio-preservatives and bio-therapeutics, we should rethink our research of the single antibacterial agent (spending time and money in using complicated technologies) and focus more on the entire bacterial product (growth media), rather standardising times and methods of CFS collection and processing.

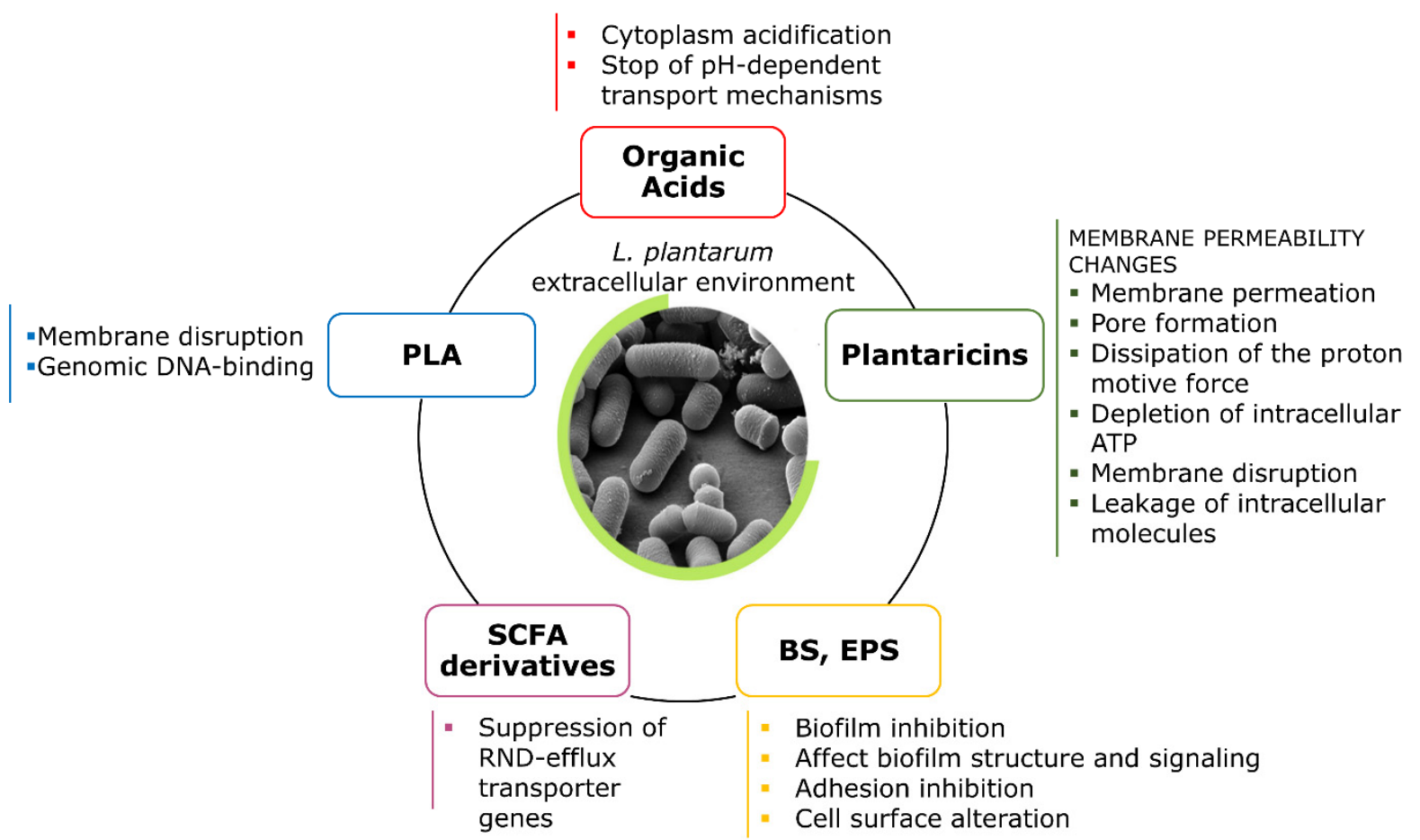

Figure 3. Different chemical nature of the principal antimicrobial agents produced by L. plantarum strains, and the suggested mechanisms underlying their antimicrobial effect. PLA: phenyl lactic acid; SCFA: short-chain fatty acids; BS: biosurfactants; EPS: exopolysaccharides.

\section{Antibacterial and Antiviral Spectrum of L. plantarum Extracellular Compounds}

A key role of probiotics is that of preventing infections in the host, maintaining a healthy and balanced intestinal microbiota; likewise, microbes intended for use as starter and food preservatives should enhance food quality and safety, limiting contamination by fastidious and potentially dangerous microbial species. Therefore, a powerful, broadspectrum antibacterial and antiviral activity against pathogens is strongly desirable, both as whole cells and as growth products/metabolites (intra and extracellular).

Table 1 shows that $L$. plantarum bacteriocins are effective against several pathogenic bacteria, including clinically relevant pathogens such as L. monocytogenes ( $50 \%$ of the reported bacteriocins), a Gram-positive species which is widespread in nature (i.e., soil, vegetation, mammalian cells), robust, able to grow at refrigeration temperatures, and also recognised for a long time as a cause of human disease. Indeed, listeriosis can determine sepsis in immunocompromised patients, meningoencephalitis and febrile gastroenteritis [112]. The activity of these proteins against L. monocytogenes, sometimes regardless of $\mathrm{pH}$ [113], besides probiotic properties and safety of the producing strain, allow the development of novel bio-preservatives, with potential use in the food industry. At present, only two bacteriocins have been given the GRAS status, being approved for use as natural food preservatives, both produced by LAB (i.e., nisin, from Lactococcus, and pediocin PA-1D, 
from Pediococcus genus) [114]. Organic acids, mainly lactic acid, produced from L. plantarum extracted from kimchi [115] and bean [73], also showed to inhibit L. monocytogenes as well as, almost to the same extent, other pathogens, making the corresponding strains potentially useful as starter culture [73,115].

L. monocytogenes, along with S. aureus and E. coli, is also considered a foodborne pathogen, as these bacteria can produce enterotoxins in contaminated food. Several different plantaricins were found to be active also against Listeria innocua, the closely related but non-pathogenic Listeria species, often used in laboratories as a surrogate organism for a better understanding of the behaviour of the pathogen during food processing [116].

Quite a few bacteriocins from L. plantarum inhibit S. aureus ( $60 \%$ of the studies reported in Table 1), one of the most common pathogens that can colonise intestine, skin tissues and perineal regions of the human host, causing severe infectious diseases, such as osteomyelitis, endocarditis, pneumonia, septicaemia, and health hazardous effects worldwide [117]. Indeed, S. aureus represents the most common microorganism causing infections in communities with very high economic burden at the social level; furthermore, it can develop considerable resistance towards conventional antimicrobial agents, with major prevalence of methicillin-resistant $S$. aureus (MRSA) and vancomycin-resistant $S$. aureus (VRSA) forms. For instance, MRSA accounted for $16 \%$ of necrotising soft tissue infections worldwide, although overall mortality is declining over the last ten years $[117,118]$. Examples of antimicrobials against these resistant forms comprise the CFS of L. plantarum strains extracted from sauerkraut [113] and from faecal microbiota [102], plantaricins LpU4 and ZJ008 from L. plantarum strains isolated from milk $[54,59]$. These extracellular compounds and their strains may represent an alternative bio-control strategy against skin infections. In addition, L. plantarum enzymes, i.e., transglycosylase and glyceraldehyde-3-phosphate dehydrogenase (GADPH), biosurfactants [90,94] and EPS [104] (in a dose-dependent manner), and, to a lesser extent, organic acids [73], all showed antagonistic activity against $S$. aureus [62].

Together with L. monocytogenes and S. aureus, E. coli is the most frequently inhibited by plantaricins (more than $50 \%$ of the L. plantarum strains/studies as reported in Table 1). This Gram-negative species represents the most prevalent commensal inhabitant of the human gastrointestinal tract, as well as one of the most common human and animal pathogens, being acknowledged as the causative agent of multiple clinical syndromes such as diarrhoeal diseases, meningitis and urinary tract infections [119]. In fact, although this bacterium is usually a benign gut commensal, some strains can acquire virulence, becoming able to cause diarrhoea in humans and other animals, and making E. coli one of the most widely studied etiologic agents worldwide [120]. Pathogenic E. coli forms causing diarrhoea have been classified into different pathotypes, including, among others, enterotoxigenic E. coli (ETEC), enteropathogenic E. coli (EPEC), Shiga toxin-producing E. coli (STEC), enteroinvasive E. coli (EIEC), enteroaggregative E. coli (EAEC), and diffusely adherent E. coli (DAEC) [120]. Interestingly, as shown in Table 1, ETEC and EPEC are inhibited mostly by organic acids and other unidentified extracellular compounds produced by several L. plantarum strains. Furthermore, EPS purified from a breast milk L. plantarum isolate demonstrated an excellent capacity to inhibit the adhesion of E. coli to epithelial human cells [107].

Plantaricins (especially Q7 [121], NC8 [122], Gt2 peptides and Cys5-4 peptide [46,51], IIA-1A5 [123], KL-1Y [58], ZJ316 [124], plantaricin 3, 5 [48]) are very active against Salmonella spp., a Gram-negative bacterium including pathotypes such as Salmonella enterica subspecies (S. enteritidis) and Salmonella enterica serotypes (S. typhimurium) (Table 1). Both can cause severe illnesses, ranging from gastroenteritis to typhoid (Typhi) and paratyphoid fever (Paratyphi), a global problem with more than 27 million cases worldwide each year $[125,126]$. Furthermore, salmonellosis, the contamination of food by Salmonella species, causes great harm to the livestock and poultry industries, thus, its prevention and control is of great importance to animal husbandry and public health [127]. Growth of Salmonella is also contrasted, through different mechanisms, including organic acids 
produced from several L. plantarum strains, EPS from L. plantarum YW32 and R315, and L-PLA from L. plantarum ZJ316 (Table 1).

Bacillus cereus is another common food contaminant with highly variable pathogenic potential ranging from strains that show little or no cytotoxic in vitro activity, to forms that are highly cytotoxic [128]. B. cereus can be responsible for two types of poisonings, depending on the toxin it produces, resulting in diarrhoea and emesis [129] (that in severe cases require hospitalisation and are sometimes fatal). B. cereus is also recognised as an aetiological agent of localised wound, eye and systemic infections [128]. Almost all plantaricins reported in Table 1 have been found active against B. cereus (corresponding to approximately $20 \%$ of the L. plantarum strains reported in Table 1) and in some cases, as for plantaricin GZ1-27, time- and dose-dependent activity was demonstrated [111]. Organic acids from L. plantarum S0/7 [73] and EPS from L. plantarum R315 [99] showed also an inhibitory activity against $B$. cereus. In addition, EPS from L. plantarum R315 were reported to inhibit $B$. cereus, other foodborne pathogens described above and Cronobacter sakazakii, an opportunistic Gram-negative bacterium that survives in very dry niches, and can contaminate food such as powdered infant milk, causing neonatal infections with high fatality rates $[130,131]$.

Pseudomonas aeruginosa is another clinically relevant species, i.e., a Gram-negative, opportunistic pathogen with a high intrinsic resistance to a wide variety of antibiotics. $P$. aeruginosa is often found in medical equipment, such as inhalers, dialysis equipment, respirators, vaporisers, in toilets and sinks [132] and, consequently, it is the cause of several kinds of hospital-acquired infections, such as catheter-associated urinary tract infections [57], ventilator-associated pneumonia, gastrointestinal infections, dermatitis, skin infections, bacteraemia, bone and joint infections, and other infections, particularly in patients with severe burns and in immunocompromised subjects (i.e., suffering from cancer or AIDS) [133]. As shown in Table 1, the antimicrobial activity of L. plantarum against $P$. aeruginosa is mainly due to plantaricins. In addition, EPS produced by L. plantarum isolated from human breast milk showed a very strong inhibition for $P$. aeruginosa, higher compared to inhibition of other foodborne pathogens described so far [107].

Plantaricins produced from L. plantarum strains isolated from various niches also inhibited Bacillus spp. (B. subtilis and B. anthracis) [134-137], Shigella spp. [59,121,136-138], Micrococcus luteus [59,122,135-137,139,140], Vibrio parahaemolyticus [122,139,141], as well as Clostridium spp. (C. butyricum, C. difficile and C. perfrigens) $[57,136]$, showing the potential for application in the food industry as well as therapeutics. Moreover, plantaricins isolated from L. plantarum strains isolated from yoghurt 'dahi', cheese and 'dosa batter' inhibited the growth and virulence properties of Gardnerella vaginalis [142,143], Kocuria rhizophila [144], and Enterobacter cloacae $[135,139]$, respectively, demonstrating the potential application of L. plantarum spp. extracellular compounds for treating bacterial vaginosis [142], human infections [145], and obesity [146].

Researchers have focused mainly on the antibacterial and antifungal properties of $L$. plantarum compounds, whereas their antiviral action has been much neglected. Table 2 reports studies, mostly in vitro, documenting such activities. Plantaricins 3 and 5 , produced by L. plantarum NIBR97, were found to exhibit antibacterial activities against a broad range of pathogens (Table 1), plus significant antiviral activities against the human pathogen influenza A virus (H3N2) (Table 2) [48]. Therefore, they were recently suggested as potential natural disinfectants, which might be an alternative to the chemical ones (alcohol- or chlorine-based preparations), for the disinfection of hands and surfaces in conditions of pandemics [48]. The proliferation of the influenza A virus was also found to be inhibited by proteinaceous compounds from L. plantarum LBP-K10 [147].

Other poorly defined extracellular metabolites from various L. plantarum strains (as reported in Table 3) could inhibit in vitro (i) Echovirus, enteroviruses isolates recovered from acute flaccid paralysis cases [148]; (ii) transmissible gastroenteritis virus (TGEV), which causes many gastrointestinal infections in piglets, characterised by diarrhoea and high mortality [149]; (iii) enterovirus Coxsackievirus B4, a challenging virus, infections of which 
have been linked to the onset of type 1 diabetes [150]; (iv) porcine epidemic diarrhoea virus $(P E D V)$, a coronavirus responsible of one of the highly contagious viral diseases in the pig industry, causing severe (sometimes fatal) diarrhoea in piglets [151]; (v) human rotavirus, i.e., the causative agent of severe diarrhoea in newborns and children worldwide [152]. Notably, the addition of prebiotics, such as those derived from microalgae, was reported to enhance both viability and antiviral effects of probiotics, as was observed for L. plantarum ATCC LP299v [153]. The anti-rotavirus action could account for beneficial effects of probiotics (mainly bifidobacteria and lactobacilli, including L. plantarum) in preventing enteric infections and alleviating diarrhoea symptoms [154]. In fact, dietary intake of L. plantarum LRCC5310, whose EPS were shown to inhibit the growth of rotavirus in vitro and in mice model [152], was subsequently found to be effective and safe in patients with rotaviral enteritis [154].

Table 3. L. plantarum strains with antimicrobial activity, whose probiotic and antipathogenic efficacy was tested in vivo (clinical and/or preclinical investigations).

\begin{tabular}{|c|c|c|c|c|}
\hline Strain Name & $\begin{array}{l}\text { Nature of } \\
\text { Antimicrobial } \\
\text { Postbiotic }\end{array}$ & $\begin{array}{l}\text { Some Pathogens } \\
\text { Inhibited }\end{array}$ & Application & Reference \\
\hline $\mathrm{Lp}^{1} 423$ & plantaricin 423 & L. monocytogenes EGDe & $\begin{array}{l}\text { Competitive exclusion } \\
\text { of } L \text {. monocytogenes } \\
\text { EGDe from the GIT of } \\
\text { mice by plantaricin } 423\end{array}$ & van Zyl WF, 2019 \\
\hline Lp LMT1-48 & SCFA $^{2}$ (hypothesised) & E. cloacae & $\begin{array}{l}\text { Antiobesity effects in } \\
\text { an } E \text {. cloacae-induced } \\
\text { high-fat diet (HFD)-fed } \\
\text { animal obesity model }\end{array}$ & Choi WJ, 2019 \\
\hline Lp ST8SH & Bacteriocin & S. aureus & $\begin{array}{l}\text { Antibacterial activity in } \\
\text { a rabbit model of } \\
\text { femoral fracture with } \\
\text { internal fixation }\end{array}$ & Xu Z, 2019 \\
\hline Lp SGLAB01 & $\mathrm{CFS}^{3}$ & V. parahaemolyticus & $\begin{array}{l}\text { Modulation of the } \\
\text { immune system and } \\
\text { increase shrimp } \\
\text { resistance to } V \text {. } \\
\text { parahaemolyticus } \\
\text { infection }\end{array}$ & Chomwong S, 2018 \\
\hline Lp ATCC 8014 & Bacteriocin & S. aureus & $\begin{array}{l}\text { Control post-operative } \\
\text { infection of mandibular } \\
\text { fracture in mice model }\end{array}$ & $\mathrm{Fu} \mathrm{T,} 2017$ \\
\hline Lp HKN01 & Bacteriocin-like & $\begin{array}{c}\text { E. coli (PTCC 1338), S. } \\
\text { Typhimurium (ATCC } \\
\text { 13311), K. pneumoniae } \\
\text { (PTCC 1290) }\end{array}$ & $\begin{array}{c}\text { Recovery of } S \text {. } \\
\text { typhimurium- infected } \\
\text { BALB/c mice }\end{array}$ & Sharafi H, 2013 \\
\hline Lp B7 & CFS (pH acid) & H. pylori & $\begin{array}{l}\text { Attenuate } H \text {. } \\
\text { pylori-induced gastric } \\
\text { inflammation in rat }\end{array}$ & Sunanliganon C, 2012 \\
\hline
\end{tabular}

${ }^{1}$ Lp: L. plantarum; ${ }^{2}$ SCFA: short-chain fatty acids; ${ }^{3}$ CFS: cell-free supernatants.

The spreading drug resistance in all cited microbial pathogens makes it difficult to treat and eradicate them and represents a severe problem for public health, requiring the development of alternative antimicrobial strategies. In this regard, the characterisation of antibacterial extracellular compounds produced by L. plantarum species opens new horizons in managing drug resistance. Particularly, bacteriocins might help to tackle antibiotic-resistant bacterial pathogens, a phenomenon that has become a worldwide threat, considering that the number of deaths per year due to antimicrobial resistance is predicted to exceed that of people who die from cancer $[155,156]$. 


\section{In Vivo Studies on L. plantarum Strains Whose Antibacterial Activity Was Earlier Characterised In Vitro}

In the medical field, L. plantarum is being investigated for an increasing number of applications such as: healing of skin wounds and burn infections [102,157,158]; treatment of mucosal infections [159,160]; protection from environmental mutagens [161,162]; amelioration of acute and chronic GIT infections $[163,164]$, gut inflammatory disorders and urinary tract infections [165]; cholesterol level-lowering properties [166]; and beneficial effects on obesity [167], diabetes [168], colon cancer [169] and cognitive impairments [170]. Such broad range of possible utilisations reflects the genomic diversity of L. plantarum, which entails its large phenotypic diversity, versatility and flexibility [171].

This paragraph briefly discusses only the studies (reported in Table 3) which combine both in vitro and in vivo approaches to assess the antimicrobial ability of L. plantarum strains/compounds and those that investigate in vivo L. plantarum strains and/or related metabolites, whose antimicrobial effectiveness was earlier characterised in vitro (i.e., reported in Table 1). Noticeably, the number of in vitro studies (Table 1) far exceeds those where such strains and/or their isolated compounds are tested through in vivo experiments (Table 3). Most likely, we have to consider that, for example, the path from the discovery of the antibacterial activity of bacteriocins (by in vitro models) to their application as therapeutic agents is long, and involves many crucial steps to advance into clinical trials, such as the use of animal models and studies on toxicity and biosafety in vivo [172].

Moreover, it is worth highlighting that, in several of the studies reported in Table 3, it is not possible to conclude whether the observed effect is caused by antimicrobials alone or by a combination of factors, e.g., by antimicrobials or the L. plantarum strain per se, by nutrient competition, or through the induction of host antimicrobial proteins.

A few preclinical studies have prospected the use of L. plantarum-derived bacteriocins as a promising tool to control post-operative infections. In two independent studies, systemic treatments based on the intravenous injection of L. plantarum bacteriocins were shown to contrast $S$. aureus bone fracture-associated infections. Using two different animal models (i.e., rabbit and mice), and upon bacteriocin treatment, the authors observed a reduction of pathogen biofilm and a decreased serum level of pro-inflammatory markers [173,174]. Coherent findings were also reported by similar investigations using bacteriocins from other lactobacilli [175]. The above-mentioned preclinical studies rely on systemic administration of the isolated antimicrobials. However, a higher therapeutic effect could be probably achieved by topic application of the antimicrobial compounds, i.e., by their direct administration at the host surface, such as oral cavity, gut, skin, and urogenital mucosa, as was also recommended for postbiotics [10]. For instance, antimicrobials could be helpful to promote healing and prevent infection at wounds, ulcers and burn sites [176-178]. However, so far, most of such studies concerning L. plantarum cell extracts and/or secreted metabolites have been carried out mainly in vitro [158].

Recently, an elegant study in mice demonstrated the key role of bacteriocin for the anti-infective action of probiotics in the host gut [179]. This study provides clear molecular evidence that protective and anti-listerial effects of a bacteriocin-producing L. plantarum strain depend just on its ability to synthesise the bacteriocin, in situ, i.e., within the gut. The authors found that oral intake of bacteriocin-negative mutants of L. plantarum 423 failed to exclude L. monocytogenes from the gastrointestinal tract of mice, while administration of wild type $L$. plantarum could not inhibit gut colonisation by recombinant $L$. monocytogenes strains expressing the plantaricin immunity proteins.

Other animal studies indicate that oral intake of L. plantarum strains endowed with antimicrobial properties can contribute to (preserve or restore) gut microbiota balance and thus support future approaches to combat enteric infections and associated GIT inflammations. For instance, Choi et al. observed antiobesity effects in mice fed with a L. plantarum strain isolated from Kimchi (a traditional Korean fermented food), and ascribed these to its in vitro inhibitory activity against obesity-inducing bacteria (i.e., Enterobacter cloacae) [146]. Likewise, a plantaricin-like heat-stable antimicrobial was isolated and partially charac- 
terised by a food isolate L. plantarum and oral administration of such strain resulted in a healthy recovery of mice infected by S. Typhimurium [180]. Moreover, a L. plantarum strain, whose supernatants inhibited Helicobacter pylori growth in vitro, could attenuate $H$. pylori-induced gastric inflammation in rats [181].

L. plantarum with antimicrobial properties may have applications even in veterinary science and livestock industry, e.g., for the management of seafood farming, as studied by Chomwong and his co-workers [182]. These authors investigated the antipathogenic effect of L. plantarum SGLAB01, a strain isolated from the gut of shrimp. Dietary supplementation of such strain was found to enhance resistance to infections by Vibrio parahaemolyticus, which is responsible for acute hepatopancreatic necrosis, a disease implying troubles in intensive shrimp aquaculture [182]. This work also demonstrates the successful use of host-derived probiotics, i.e., microbes isolated from the digestive tract of the animal that is itself the target of the microbe-based therapeutic strategy. Such an approach reflects an increasing and up-to-date awareness that the animal and, specifically, human gut provides rich and as yet poorly explored reservoirs of potentially curative microorganisms, i.e., the so-called next-generation probiotics [183]. In very recent preclinical and clinical studies, (alterations of) some of these next-generation probiotics, identified as members of the human gut microbiota, have been associated with diverse diseases and hence have been indicated to own promising therapeutic potentials, e.g., for the treatment of diabetes and other endocrine/metabolism-related diseases [184].

\section{Conclusions}

As supported by the papers discussed in the present review, it is undoubtful that antimicrobial properties are of utmost relevance for the health-promoting effect of probiotics. Although several in vitro studies suggest a vast therapeutic potential for the antimicrobials from L. plantarum, to date, only a handful of investigations have explored the feasibility of their applications in vivo. Even if L. plantarum antimicrobials were found to be active against a broad spectrum of pathogens, just a few of them have been subsequently proven to prevent or ameliorate disease phenotypes in animal models. The numerical discrepancy between in vitro studies on L. plantarum antimicrobials and in vivo investigations might depend on the demanding organisation and management of the protocols required for experiments on animals, and then, in humans. A limiting factor may also be the isolation or the synthesis of adequate amounts of antimicrobial compounds to conduct in vivo investigations. In addition, comparative studies to assess the effectiveness of the isolated antimicrobial compound and the corresponding strain, in the form of viable cells, would be very useful and could indicate the way forward for probiotic research. Therapies based on probiotics, e.g., L. plantarum and probiotic-derived factors, have a high potential for the treatment of disorders, especially infections and gastrointestinal tract (GIT) diseases, and much research is still needed to define and consolidate it.

Author Contributions: Conceptualization, Methodology, Formal Analysis, Investigation, Data Curation, Writing-Original Draft Preparation, M.T.R. and D.F.; Data Curation, Manuscript Revision, P.R., V.C. and D.D.; Supervision, Project Administration, Funding Acquisition, D.F. and G.S. All authors have read and agreed to the published version of the manuscript.

Funding: M.T.R. is the beneficiary of researcher's contract for the project no. UNIFG171- CUP D74I19003340002, as part of the initiative "Research for Innovation (REFIN)- POR PUGLIA FESR FSE 2014- 2020- Azione 10.4"; P.R. is the beneficiary of a grant by MIUR in the framework of 'AIM: Attraction and International Mobility' (PON R\&I2014-2020) (practice code D74I18000190001). This work was partially supported by PON project "Conservabilità, qualità e sicurezza dei prodotti ortofrutticoli ad alto contenuto di servizio" - POFACS - CUP B74I20000120005.

Conflicts of Interest: The authors declare no conflict of interest. 


\section{References}

1. Wang, Y.; Wu, J.; Lv, M.; Shao, Z.; Hungwe, M.; Wang, J.; Bai, X.; Xie, J.; Wang, Y.; Geng, W. Metabolism Characteristics of Lactic Acid Bacteria and the Expanding Applications in Food Industry. Front. Bioeng. Biotechnol. 2021, 9, 612285. [CrossRef] [PubMed]

2. EFSA. Scientific opinion of the panel on biological hazards on the request from EFSA on the maintenance of the list of QPS microorganisms intentionally added to food or feed. EFSA J. 2008, 928, 1-48.

3. Gheziel, C.; Russo, P.; Arena, M.P.; Spano, G.; Ouzari, H.-I.; Kheroua, O.; Saidi, D.; Fiocco, D.; Kaddouri, H.; Capozzi, V. Evaluating the Probiotic Potential of Lactobacillus plantarum Strains from Algerian Infant Feces: Towards the Design of Probiotic Starter Cultures Tailored for Developing Countries. Probiotics Antimicrob. Proteins 2019, 11, 113-123. [CrossRef] [PubMed]

4. Seddik, H.A.; Bendali, F.; Gancel, F.; Fliss, I.; Spano, G.; Drider, D. Lactobacillus plantarum and Its Probiotic and Food Potentialities. Probiotics Antimicrob. Proteins 2017, 9, 111-122. [CrossRef] [PubMed]

5. Hill, C.; Guarner, F.; Reid, G.; Gibson, G.R.; Merenstein, D.J.; Pot, B.; Morelli, L.; Canani, R.B.; Flint, H.J.; Salminen, S.; et al. Expert consensus document: The international scientific association for probiotics and prebiotics consensus statement on the scope and appropriate use of the term probiotic. Nat. Rev. Gastroenterol. Hepatol. 2014, 11, 506-514. [CrossRef]

6. Fiocco, D.; Longo, A.; Arena, M.P.; Russo, P.; Spano, G.; Capozzi, V. How probiotics face food stress: They get by with a little help. Crit. Rev. Food Sci. Nutr. 2020, 60, 1552-1580. [CrossRef]

7. LeBlanc, J.G.; Chain, F.; Martín, R.; Humaran, L.G.B.; Courau, S.; Langella, P. Beneficial effects on host energy metabolism of short-chain fatty acids and vitamins produced by commensal and probiotic bacteria. Microb. Cell Fact. 2017, 16, 79. [CrossRef]

8. Arena, M.P.; Russo, P.; Capozzi, V.; López, P.; Fiocco, D.; Spano, G. Probiotic abilities of riboflavin-overproducing Lactobacillus strains: A novel promising application of probiotics. Appl. Microbiol. Biotechnol. 2014, 98, 7569-7581. [CrossRef]

9. Markowiak, P.; Śliżewska, K. Effects of Probiotics, Prebiotics, and Synbiotics on Human Health. Nutrients 2017, 9, 1021. [CrossRef]

10. Salminen, S.; Collado, M.C.; Endo, A.; Hill, C.; Lebeer, S.; Quigley, E.M.M.; Sanders, M.E.; Shamir, R.; Swann, J.R.; Szajewska, H.; et al. The International Scientific Association of Probiotics and Prebiotics (ISAPP) consensus statement on the definition and scope of postbiotics. Nat. Rev. Gastroenterol. Hepatol. 2021, 18, 649-667. [CrossRef]

11. Aguilar-Toalá, J.E.; Arioli, S.; Behare, P.; Belzer, C.; Berni Canani, R.; Chatel, J.M.; D'Auria, E.; de Freitas, M.Q.; Elinav, E.; Esmerino, E.A.; et al. Postbiotics-When simplification fails to clarify. Nat. Rev. Gastroenterol. Hepatol. 2021, 18, 825-826. [CrossRef] [PubMed]

12. Salminen, S.; Collado, M.C.; Endo, A.; Hill, C.; Lebeer, S.; Quigley, E.M.; Sanders, M.E.; Shamir, R.; Swann, J.R.; Szajewska, H.; et al. Reply to: Postbiotics-When simplification fails to clarify. Nat. Rev. Gastroenterol. Hepatol. 2021, 18, 827-828. [CrossRef]

13. Prabhurajeshwar, C.; Chandrakanth, K. Evaluation of antimicrobial properties and their substances against pathogenic bacteria in-vitro by probiotic Lactobacilli strains isolated from commercial yoghurt. Clin. Nutr. Exp. 2019, 23, 97-115. [CrossRef]

14. Arena, M.P.; Capozzi, V.; Russo, P.; Drider, D.; Spano, G.; Fiocco, D. Immunobiosis and probiosis: Antimicrobial activity of lactic acid bacteria with a focus on their antiviral and antifungal properties. Appl. Microbiol. Biotechnol. 2018, 102, 9949-9958. [CrossRef]

15. Rodríguez-Sánchez, S.; Fernández-Pacheco, P.; Seseña, S.; Pintado, C.; Palop, M.L. Selection of probiotic Lactobacillus strains with antimicrobial activity to be used as biocontrol agents in food industry. LWT-Food Sci. Technol. 2021, 143, 111142. [CrossRef]

16. De Simone, N.; Capozzi, V.; de Chiara, M.L.V.; Amodio, M.L.; Brahimi, S.; Colelli, G.; Drider, D.; Spano, G.; Russo, P. Screening of Lactic Acid Bacteria for the Bio-Control of Botrytis cinerea and the Potential of Lactiplantibacillus plantarum for Eco-Friendly Preservation of Fresh-Cut Kiwifruit. Microorganisms 2021, 9, 773. [CrossRef]

17. Umu, Ö.C.; Bäuerl, C.; Oostindjer, M.; Pope, P.B.; Hernández, P.E.; Pérez-Martínez, G.; Diep, D. The Potential of Class II Bacteriocins to Modify Gut Microbiota to Improve Host Health. PLoS ONE 2016, 11, e0164036. [CrossRef]

18. Garcia-Gutierrez, E.; Mayer, M.J.; Cotter, P.D.; Narbad, A. Gut microbiota as a source of novel antimicrobials. Gut Microbes 2019, 10, 1-21. [CrossRef]

19. Wang, G.; Yu, Y.; Garcia-Gutierrez, E.; Jin, X.; He, Y.; Wang, L.; Tian, P.; Liu, Z.; Zhao, J.; Zhang, H.; et al. Lactobacillus acidophilus JCM 1132 strain and its mutant with different bacteriocin-producing behaviour have various in situ effects on the gut microbiota of healthy mice. Microorganisms 2020, 8, 49. [CrossRef]

20. Russo, P.; Arena, M.P.; Fiocco, D.; Capozzi, V.; Drider, D.; Spano, G. Lactobacillus plantarum with broad antifungal activity: A promising approach to increase safety and shelf-life of cereal-based products. Int. J. Food Microbiol. 2017, 247, 48-54. [CrossRef]

21. Hernández-Aquino, S.; Miranda-Romero, L.A.; Fujikawa, H.; Maldonado-Simán, E.J.; Alarcón-Zuñiga, B. Antibacterial Activity of Lactic Acid Bacteria to Improve Shelf Life of Raw Meat. Biocontrol Sci. 2019, 24, 185-192. [CrossRef]

22. Fuochi, V.; Emma, R.; Furneri, P. Bacteriocins, A Natural Weapon Against Bacterial Contamination for Greater Safety and Preservation of Food: A Review. Curr. Pharm. Biotechnol. 2021, 22, 216-231. [CrossRef] [PubMed]

23. Gaspar, C.; Donders, G.G.; Palmeira-de-Oliveira, R.; Queiroz, J.A.; Tomaz, C.; Martinez-de-Oliveira, J.; Palmeira-de-Oliveira, A. Bacteriocin production of the probiotic Lactobacillus acidophilus KS400. AMB Express 2018, 8, 153. [CrossRef]

24. Hertzberger, R.; Arents, J.; Dekker, H.L.; Pridmore, R.D.; Gysler, C.; Kleerebezem, M.; de Mattos, M.J.T. H ${ }_{2} \mathrm{O}_{2}$ production in species of the Lactobacillus acidophilus group: A central role for a novel NADH-dependent flavin reductase. Appl. Environ. Microbiol. 2014, 80, 2229-2239. [CrossRef]

25. das Neves Selis, N.; de Oliveira, H.B.M.; Leão, H.F.; Dos Anjos, Y.B.; Sampaio, B.A.; Correia, T.M.L.; Almeida, C.F.; Pena, L.S.C.; Reis, M.M.; Brito, T.L.S.; et al. Lactiplantibacillus plantarum strains isolated from spontaneously fermented cocoa exhibit potential probiotic properties against Gardnerella vaginalis and Neisseria gonorrhoeae. BMC Microbiol. 2021, 21, 198. [CrossRef] [PubMed] 
26. Zhou, Q.; Gu, R.; Li, P.; Lu, Y.; Chen, L.; Gu, Q. Anti-Salmonella mode of action of natural l-phenyl lactic acid purified from Lactobacillus plantarum ZJ316. Appl. Microbiol. Biotechnol. 2020, 104, 5283-5292. [CrossRef] [PubMed]

27. Zhang, X.; Zhang, S.; Shi, Y.; Shen, F.; Wang, H. A new high phenyl lactic acid-yielding Lactobacillus plantarum IMAU10124 and a comparative analysis of lactate dehydrogenase gene. FEMS Microbiol. Lett. 2014, 356, 89-96. [CrossRef]

28. Flynn, J.; Ryan, A.; Hudson, S. Pre-formulation and delivery strategies for the development of bacteriocins as next generation antibiotics. Eur. J. Pharm. Biopharm. 2021, 165, 149-163. [CrossRef] [PubMed]

29. Fijan, S.; Frauwallner, A.; Langerholc, T.; Krebs, B.; ter Haar née Younes, J.A.; Heschl, A.; Mičetić Turk, D.; Rogelj, I. Efficacy of Using Probiotics with Antagonistic Activity against Pathogens of Wound Infections: An Integrative Review of Literature. BioMed Res Int. 2019, 2019, 7585486. [CrossRef]

30. Pop, O.L.; Pop, C.R.; Dufrechou, M.; Vodnar, D.C.; Socaci, S.A.; Dulf, F.V.; Minervini, F.; Suharoschi, R. Edible Films and Coatings Functionalization by Probiotic Incorporation: A Review. Polymers 2020, 12, 12. [CrossRef]

31. Gibson, G.R.; Hutkins, R.; Sanders, M.E.; Prescott, S.L.; Reimer, R.A.; Salminen, S.J.; Scott, K.; Stanton, C.; Swanson, K.S.; Cani, P.D.; et al. Expert consensus document: The International Scientific Association for Probiotics and Prebiotics (ISAPP) consensus statement on the definition and scope of prebiotics. Nat. Rev. Gastroenterol. Hepatol. 2017, 14, 491-502. [CrossRef]

32. Swanson, K.S.; Gibson, G.R.; Hutkins, R.; Reimer, R.A.; Reid, G.; Verbeke, K.; Scott, K.P.; Holscher, H.D.; Azad, M.B.; Delzenne, N.M.; et al. Expert consensus document: The International Scientific Association for Probiotics and Prebiotics (ISAPP) consensus statement on the definition and scope of synbiotics. Nat. Rev. Gastroenterol. Hepatol. 2020, 17, 687-701.

33. Esposito, S.; Soto-Martinez, M.E.; Feleszko, W.; Jones, M.H.; Shen, K.-L.; Schaad, U.B. Nonspecific immunomodulators for recurrent respiratory tract infections, wheezing and asthma in children: A systematic review of mechanistic and clinical evidence. Curr. Opin. Allergy Clin. Immunol. 2018, 18, 198-209. [CrossRef]

34. Aguilar-Toalá, J.E.; Garcia-Varela, R.; Garcia, H.S.; Mata-Haro, V.; González-Córdova, A.F.; Vallejo-Cordoba, B.; HernándezMendoza, A. Postbiotics: An evolving term within the functional foods field. Trends Food Sci. Technol. 2018, 75, 105-114. [CrossRef]

35. Pankey GA, S.L. Clinical relevance of bacteriostatic versus bactericidal activity in the treatment of gram-positive bacterial infections. Clin. Infect. Dis. 2004, 38, 864-870. [CrossRef]

36. O'Connor, P.M.; Kuniyoshi, T.M.; Oliveira, R.P.; Hill, C.; Ross, R.P.; Cotter, P.D. Antimicrobials for food and feed; a bacteriocin perspective. Curr. Opin. Biotechnol. 2020, 61, 160-167. [CrossRef]

37. Maldonado, A.; Jiménez-Díaz, R.; Ruiz-Barba, J.L. Induction of plantaricin production in Lactobacillus plantarum NC8 after coculture with specific gram-positive bacteria is mediated by an autoinduction mechanism. J. Bacteriol. 2004, 186, 1556-1564. [CrossRef]

38. Rojo-Bezares, B.; Sáenz, Y.; Navarro, L.; Zarazaga, M.; Ruiz-Larrea, F.; Torres, C. Coculture-inducible bacteriocin activity of Lactobacillus plantarum strain J23 isolated from grape must. Food Microbiol. 2007, 24, 482-491. [CrossRef]

39. Man LL, X.D. LuxS-mediated quorum sensing system in Lactobacillus plantarum NMD-17 from koumiss: Induction of plantaricin MX in co-cultivation with certain lactic acid bacteria. Folia Microbiol. 2021, 66, 855-871. [CrossRef]

40. Wu, A.; Fu, Y.; Kong, L.; Shen, Q.; Liu, M.; Zeng, X.; Wu, Z.; Guo, Y.; Pan, D. Production of a Class IIb Bacteriocin with Broad-spectrum Antimicrobial Activity in Lactiplantibacillus plantarum RUB1. Probiotics Antimicrob. Proteins 2021. [CrossRef]

41. Marco, M.L.; Bongers, R.S.; De Vos, W.M.; Kleerebezem, M. Spatial and temporal expression of Lactobacillus plantarum genes in the gastrointestinal tracts of mice. Appl. Environ. Microbiol. 2007, 73, 124-132. [CrossRef]

42. Bove, P.; Russo, P.; Capozzi, V.; Gallone, A.; Spano, G.; Fiocco, D. Lactobacillus plantarum passage through an oro-gastro-intestinal tract simulator: Carrier matrix effect and transcriptional analysis of genes associated to stress and probiosis. Microbiol. Res. 2013, 168, 351-359. [CrossRef] [PubMed]

43. Meijerink, M.; van Hemert, S.; Taverne, N.; Wels, M.; De Vos, P.; Bron, P.A.; Savelkoul, H.F.; van Bilsen, J.; Kleerebezem, M.; Wells, J.M. Identification of genetic loci in Lactobacillus plantarum that modulate the immune response of dendritic cells using comparative genome hybridization. PLoS ONE 2010, 5, e10632. [CrossRef] [PubMed]

44. van Hemert, S.; Meijerink, M.; Molenaar, D.; Bron, P.A.; de Vos, P.; Kleerebezem, M.; Wells, J.M.; Marco, M.L. Identification of Lactobacillus plantarum genes modulating the cytokine response of human peripheral blood mononuclear cells. BMC Microbiol. 2010, 10, 293. [CrossRef]

45. Golneshin, A.; Gor, M.C.; Williamson, N.; Vezina, B.; Van, T.T.H.; May, B.K.; Smith, A.T. Discovery and characterisation of circular bacteriocin plantacyclin B21AG from Lactiplantibacillus plantarum B21. Heliyon 2020, 6, e04715. [CrossRef]

46. Tenea, G.N. Peptide Extracts from Native Lactic Acid Bacteria Generate Ghost Cells and Spheroplasts upon Interaction with Salmonella enterica, as Promising Food Antimicrobials. BioMed Res. Int. 2020, 2020, 6152356. [CrossRef]

47. Arief, I.I.; Budiman, C.; Jenie, B.S.L.; Andreas, E.; Yuneni, A. Plantaricin IIA-1A5 from Lactobacillus plantarum IIA-1A5 displays bactericidal activity against Staphylococcus aureus. Benef. Microbes 2015, 6, 603-613. [CrossRef]

48. Kim, S.W.; Kang, S.I.; Shin, D.H.; Oh, S.Y.; Lee, C.W.; Yang, Y.; Son, Y.K.; Yang, H.S.; Lee, B.H.; An, H.J.; et al. Potential of cell-free supernatant from lactobacillus plantarum nibr97, including novel bacteriocins, as a natural alternative to chemical disinfectants. Pharmaceuticals 2020, 13, 266. [CrossRef]

49. Jiang, H.; Tang, X.; Zhou, Q.; Zou, J.; Li, P.; Breukink, E.; Gu, Q. Plantaricin NC8 from Lactobacillus plantarum causes cell membrane disruption to Micrococcus luteus without targeting lipid II. Appl. Microbiol. Biotechnol. 2018, 102, 7465-7473. [CrossRef] 
50. Tenea, G.N.; Pozo, T.D. Antimicrobial Peptides from Lactobacillus plantarum UTNGt2 Prevent Harmful Bacteria Growth on Fresh Tomatoes. J. Microbiol. Biotechnol. 2019, 29, 1553-1560. [CrossRef]

51. Tenea, G.N.; Guaña, J.M. Inhibitory substances produced by native Lactobacillus plantarum UTNCys5-4 control microbial population growth in meat. J. Food Qual. 2019, 2019, 9516981. [CrossRef]

52. Shapiro, R.S. Antimicrobial-induced DNA damage and genomic instability in microbial pathogens. PLoS Pathog. 2015, 11, e1004678. [CrossRef]

53. Barbosa, M.S.; Todorov, S.D.; Ivanova, I.V.; Belguesmia, Y.; Choiset, Y.; Rabesona, H.; Chobert, J.M.; Haertlé, T.; Franco, B.D.G.M. Characterization of a two-peptide plantaricin produced by Lactobacillus plantarum MBSa4 isolated from Brazilian salami. Food Control 2016, 60, 103-112. [CrossRef]

54. Milioni, C.; Martínez, B.; Degl'Innocenti, S.; Turchi, B.; Fratini, F.; Cerri, D.; Fischetti, R. A novel bacteriocin produced by Lactobacillus plantarum LpU4 as a valuable candidate for biopreservation in artisanal raw milk cheese. Dairy Sci. Technol. 2015, 95, 479-494. [CrossRef]

55. Atrih, A.; Rekhif, N.; Moir, A.J.; Lebrihi, A.; Lefebvre, G. Mode of action, purification and amino acid sequence of plantaricin C19, an anti-Listeria bacteriocin produced by Lactobacillus plantarum C19. Int. J. Food Microbiol. 2001, 68, 93-104. [CrossRef]

56. Hernández, D.; Cardell, E.; Zarate, V. Antimicrobial activity of lactic acid bacteria isolated from Tenerife cheese: Initial characterization of plantaricin TF711, a bacteriocin-like substance produced by Lactobacillus plantarum TF711. J. Appl. Microbiol. 2005, 99, 77-84. [CrossRef]

57. Mohapatra, A.R.; Jeevaratnam, K. Inhibiting bacterial colonization on catheters: Antibacterial and antibiofilm activities of bacteriocins from Lactobacillus plantarum SJ33. J. Glob. Antimicrob. Resist. 2019, 19, 85-92. [CrossRef]

58. Rumjuankiat, K.; Perez, R.H.; Pilasombut, K.; Keawsompong, S.; Zendo, T.; Sonomoto, K.; Nitisinprasert, S. Purification and characterization of a novel plantaricin, KL-1Y, from Lactobacillus plantarum KL-1. World J. Microbiol. Biotechnol. 2015, 31, 983-994. [CrossRef]

59. Zhu, X.; Zhao, Y.; Sun, Y.; Gu, Q. Purification and characterisation of plantaricin ZJ008, a novel bacteriocin against Staphylococcus spp. from Lactobacillus plantarum ZJ008. Food Chem. 2014, 165, 216-223. [CrossRef]

60. Zhang, H.; Liu, L.; Hao, Y.; Zhong, S.; Liu, H.; Han, T.; Xie, Y. Isolation and partial characterization of a bacteriocin produced by Lactobacillus plantarum BM-1 isolated from a traditionally fermented Chinese meat product. Microbiol. Immunol. 2013, 57, 746-755. [CrossRef]

61. Wang, H.; Xie, Y.; Zhang, H.; Jin, J.; Zhang, H. Quantitative proteomic analysis reveals the influence of plantaricin BM-1 on metabolic pathways and peptidoglycan synthesis in Escherichia coli K12. PLoS ONE 2020, 15, e0231975. [CrossRef]

62. Ong, J.S.; Taylor, T.D.; Wong, C.B.; Khoo, B.Y.; Sasidharan, S.; Choi, S.B.; Ohno, H.; Liong, M.T. Extracellular transglycosylase and glyceraldehyde-3-phosphate dehydrogenase attributed to the anti-staphylococcal activity of Lactobacillus plantarum USM8613. J. Biotechnol. 2019, 300, 20-31. [CrossRef]

63. de Freire Bastos, M.D.C.; Coelho, M.L.V.; da Silva Santos, O.C. Resistance to bacteriocins produced by gram-positive bacteria. Microbiology 2015, 161, 683-700. [CrossRef]

64. Rashid, R.; Veleba, M.; Kline, K.A. Focal targeting of the bacterial envelope by antimicrobial peptides. Front. Cell Dev. Biol. 2016, 4, 55. [CrossRef]

65. Mathur, H.; Field, D.; Rea, M.C.; Cotter, P.D.; Hill, C.; Ross, R.P. Fighting biofilms with lantibiotics and other group of bacteriocins. NPJ Biofilms. Microbiomes 2018, 4, 9.

66. Kumariya, R.; Garsa, A.K.; Rajput, Y.S.; Sood, S.K.; Akhtar, N.; Patel, S.; Kumariya, R.; Garsa, A.K.; Rajput, Y.S.; Sood, S.K.; et al. Bacteriocins: Classification, synthesis, mechanism of action and resistance development in food spoilage causing bacteria. Microb. Pathog. 2019, 128, 171-177. [CrossRef]

67. Ołdak, A.; Zielińska, D.; Rzepkowska, A.; Kołozyn-Krajewska, D. Comparison of Antibacterial Activity of Lactobacillus plantarum Strains Isolated from Two Different Kinds of Regional Cheeses from Poland: Oscypek and Korycinski Cheese. BioMed Res. Int. 2017, 2017, 6820369. [CrossRef]

68. Tejerosariñena, S.; Barlow, J.; Costabile, A.; Gibson, G.R.; Rowland, I. In vitro evaluation of the antimicrobial activity of a range of probiotics against pathogens: Evidence for the effects of organic acids. Anaerobe 2012, 18, 530-538. [CrossRef]

69. Stratford, M.; Eklund, T. Organic acids and esters. In Food Preservatives; Springer: Boston, MA, USA, 2003.

70. Li, X.; Xu, W.; Yang, J.; Zhao, H.; Pan, C.; Ding, X.; Zhang, Y. Effects of applying lactic acid bacteria to the fermentation on a mixture of corn steep liquor and air-dried rice straw. Anim. Nutr. (Zhongguo Xu Mu Shou Yi Xue Hui) 2016, 2, 229-233. [CrossRef]

71. Axelsson, L.; Salminen, S.; von Wright, A. (Eds.) Lactic Acid Bacteria: Microbiology and Functional Aspects, 2nd ed.; Marcel Dekker: New York, NY, USA, 1998.

72. Thu, T.V.; Foo, H.L.; Loh, T.C.; Bejo, M.H. Inhibitory activity and organic acid concentrations of metabolite combinations produced by various strains of Lactobacillus plantarum. Afr. J. Biotechnol. 2013, 10, 1359-1363.

73. Saelim, K.; Jampaphaeng, K.; Maneerat, S. Functional properties of Lactobacillus plantarum S0/7 isolated fermented stinky bean (Sa Taw Dong) and its use as a starter culture. J. Funct. Foods 2017, 38, 370-377. [CrossRef]

74. Schnürer, J.; Magnusson, J. Antifungal lactic acid bacteria as biopreservatives. Trends Food Sci. Technol. 2005, 16, 70-78. [CrossRef]

75. Presser, K.A.; Ratkowsky, D.A.; Ross, T. Modelling the growth rate of Escherichia coli as a function of $\mathrm{pH}$ and lactic acid concentration. Appl. Environ. Microbiol. 1997, 63, 2355-2360. [CrossRef] 
76. Lin, T.H.; Pan, T.M. Characterization of an antimicrobial substance produced by Lactobacillus plantarum NTU 102. J. Microbiol. Immunol. Infect. 2019, 52, 409-417. [CrossRef]

77. Matsuo, T.; Nakamura, K.; Kodama, T.; Mikami, T.; Hiyoshi, H.; Tsuchiya, T.; Ogawa, W.; Kuroda, T. Characterization of all RND-type multidrug efflux transporters in Vibrio parahaemolyticus. Microbiologyopen 2013, 2, 725-742. [CrossRef]

78. Wu, W.; Deng, G.; Liu, C.; Gong, X.; Ma, G.; Yuan, Q.; Yang, E.; Li, X.; Luo, Y. Optimization and Multiomic Basis of Phenyllactic Acid Overproduction by Lactobacillus plantarum. J. Agric. Food Chem. 2020, 68, 1741-1749. [CrossRef]

79. Mu, W.; Yu, S.; Zhu, L.; Zhang, T.; Jiang, B. Recent research on 3-phenyllactic acid, a broad-spectrum antimicrobial compound. Appl. Microbiol. Biotechnol. 2012, 95, 1155-1163. [CrossRef]

80. Dao, Y.; Zhang, K.; Lu, X.; Lu, Z.; Liu, C.; Liu, M.; Luo, Y. Role of Glucose and 2-Oxoglutarate/Malate Translocator (OMT1) in the Production of Phenyllactic Acid and p-Hydroxyphenyllactic Acid, Two Food-Borne Pathogen Inhibitors. J. Agric. Food Chem. 2019, 67, 5820-5826. [CrossRef]

81. Dieuleveux, V.; Lemarinier, S.; Gueguen, M. Antimicrobial spectrum and target site of D-3-phenyllactic acid. Int. J. Food Microbiol. 1998, 40, 177-183. [CrossRef]

82. Lavermicocca, P.; Valerio, F.; Evidente, A.; Lazzaroni, S.; Corsetti, A.; Gobbetti, M. Purification and characterization of novel antifungal compounds from the sourdough Lactobacillus plantarum strain 21B. Appl. Environ. Microbiol. 2000, 66, 4084-4090. [CrossRef]

83. Ning, Y.; Yan, A.; Yang, K.; Wang, Z.; Li, X.; Jia, Y. Antibacterial activity of phenyllactic acid against Listeria monocytogenes and Escherichia coli by dual mechanisms. Food Chem. 2017, 228, 533-540. [CrossRef]

84. Sorrentino, E.; Tremonte, P.; Succi, M.; Iorizzo, M.; Pannella, G.; Lombardi, S.J.; Sturchio, M.; Coppola, R. Detection of antilisterial activity of 3- phenyllactic acid using Listeria innocua as amodel. Front Microbiol. 2018, 9, 1373-1381. [CrossRef]

85. Wang, C.; Chang, T.; Yang, H.; Cui, M. Surface physiological changes induced by lactic acid on pathogens in consideration of pKa and $\mathrm{pH}$. Food Control 2014, 46, 525-531. [CrossRef]

86. Zhang, J.; Zhang, C.; Lei, P.; Xin, X.; Liu, D.; Yi, H. Isolation, purification, identification, and discovery of the antibacterial mechanism of ld-phenyllactic acid produced by Lactiplantibacillus plantarum CXG9 isolated from a traditional Chinese fermented vegetable. Food Control 2022, 132, 108490. [CrossRef]

87. Satpute, S.K.; Kulkarni, G.R.; Banpurkar, A.G.; Banat, I.M.; Mone, N.S.; Patil, R.H.; Cameotra, S.S. Biosurfactant/s from Lactobacilli species: Properties, challenges and potential biomedical applications. J. Basic Microbiol. 2016, 56, 1140-1158. [CrossRef]

88. Singh, S.S.; Akhtar, M.N.; Sharma, D.; Mandal, S.M.; Korpole, S. Characterization of Iturin V, a Novel Antimicrobial Lipopeptide from a Potential Probiotic Strain Lactobacillus sp. M31. Probiotics Antimicrob. Proteins 2021. [CrossRef]

89. Vecino, X.; Rodríguez-López, L.; Ferreira, D.; Cruz, J.M.; Moldes, A.B.; Rodrigues, L. Bioactivity of glycolipopeptide cell-bound biosurfactants against skin pathogens. Int. J. Biol. Macromol. 2018, 109, 971-979. [CrossRef]

90. Madhu, A.N.; Prapulla, S.G. Evaluation and functional characterization of a biosurfactant produced by Lactobacillus plantarum CFR 2194. Appl. Biochem. Biotechnol. 2014, 172, 1777-1789. [CrossRef]

91. Sakr, E.A.E.; Ahmed, H.A.E.; Abo Saif, F.A.A. Characterization of low-cost glycolipoprotein biosurfactant produced by Lactobacillus plantarum 60 FHE isolated from cheese samples using food wastes through response surface methodology and its potential as antimicrobial, antiviral, and anticancer activi. Int. J. Biol. Macromol. 2021, 170, 94-106. [CrossRef]

92. Sharma, D.; Saharan, B.S.; Chauhan, N.; Bansal, A.; Procha, S. Production and structural characterization of Lactobacillus helveticus derived biosurfactant. Sci. World J. 2014, 2014, 493548. [CrossRef]

93. Ghasemi, A.; Moosavi-Nasab, M.; Behzadnia, A.; Rezaei, M. Enhanced biosurfactant production with low-quality date syrup by Lactobacillus rhamnosus using a fed-batch fermentation. Food Sci. Biotechnol. 2018, 27, 1137-1144. [CrossRef]

94. Yan, X.; Gu, S.; Cui, X.; Shi, Y.; Wen, S.; Chen, H.; Ge, J. Antimicrobial, anti-adhesive and anti-biofilm potential of biosurfactants isolated from Pediococcus acidilactici and Lactobacillus plantarum against Staphylococcus aureus CMCC26003. Microb. Pathog. 2019, 127, 12-20. [CrossRef]

95. Singh, S.; Bhatia, R.; Khare, P.; Sharma, S.; Rajarammohan, S.; Bishnoi, M.; Bhadada, S.K.; Sharma, S.S.; Kaur, J.; Kondepudi, K.K. Anti-inflammatory Bifidobacterium strains prevent dextran sodium sulfate induced colitis and associated gut microbial dysbiosis in mice. Sci. Rep. 2020, 10, 18597. [CrossRef]

96. Karina, S.; Euston, E.S. Sustainable microbial biosurfactants and bioemulsifiers for commercial exploitation. Process Biochem. 2019, $85,143-155$.

97. Sambanthamoorthy, K.; Feng, X.; Patel, R.; Patel, S.; Paranavitana, C. Antimicrobial and antibiofilm potential of biosurfactants isolated from lactobacilli against multi-drug-resistant pathogens. BMC Microbiol. 2014, 14, 197. [CrossRef]

98. Lee, I.C.; Caggianiello, G.; van Swam, I.I.; Taverne, N.; Meijerink, M.; Bron, P.A.; Spano, G.; Kleerebezem, M. Strain-Specific Features of Extracellular Polysaccharides and Their Impact on Lactobacillus plantarum-Host Interactions. Appl. Environ. Microbiol. 2016, 82, 3959-3970. [CrossRef]

99. Li, S.; Huang, R.; Shah, N.P.; Tao, X.; Xiong, Y.; Wei, H. Antioxidant and antibacterial activities of exopolysaccharides from Bifidobacterium bifidum WBIN03 and Lactobacillus plantarum R315. J. Dairy Sci. 2014, 97, 7334-7343. [CrossRef]

100. Mahdhi, A.; Leban, N.; Chakroun, I.; Bayar, S.; Mahdouani, K.; Majdoub, H.; Kouidhi, B. Use of extracellular polysaccharides, secreted by Lactobacillus plantarum and Bacillus spp., as reducing indole production agents to control biofilm formation and efflux pumps inhibitor in Escherichia coli. Microb. Pathog. 2018, 125, 448-453. [CrossRef] 
101. Song, Y.; Sun, M.; Feng, L.; Liang, X.; Song, X.; Mu, G.; Tuo, Y.; Jiang, S.; Qian, F. Antibiofilm Activity of Lactobacillus plantarum 12 Exopolysaccharides against Shigella flexneri. Appl. Environ. Microbiol. 2020, 86, e00694-20. [CrossRef]

102. Onbas, T.; Osmanagaoglu, O.; Kiran, F. Potential Properties of Lactobacillus plantarum F-10 as a Bio-control Strategy for Wound Infections. Probiotics Antimicrob. Proteins 2019, 11, 1110-1123. [CrossRef]

103. Liu, Z.; Zhang, Z.; Qiu, L.; Zhang, F.; Xu, X.; Wei, H.; Tao, X. Characterization and bioactivities of the exopolysaccharide from a probiotic strain of Lactobacillus plantarum WLPL04. J. Dairy Sci. 2017, 100, 6895-6905. [CrossRef]

104. Wang, J.; Zhao, X.; Yang, Y.; Zhao, A.; Yang, Z. Characterization and bioactivities of an exopolysaccharide produced by Lactobacillus plantarum YW32. Int. J. Biol. Macromol. 2015, 74, 119-126. [CrossRef]

105. Min, Z.; Xiaona, H.; Aziz, T.; Jian, Z.; Zhennai, Y. Exopolysaccharides from Lactobacillus plantarum YW11 improve immune response and ameliorate inflammatory bowel disease symptoms. Acta Biochim. Pol. 2020, 67, 485-493.

106. Zhou, X.; Zhang, K.; Qi, W.; Zhou, Y.; Hong, T.; Xiong, T.; Xie, M.; Nie, S. Exopolysaccharides from Lactobacillus plantarum NCU116 Enhances Colonic Mucosal Homeostasis by Controlling Epithelial Cell Differentiation and c-Jun/Muc2 Signaling. J. Agric. Food Chem. 2019, 67, 9831-9839. [CrossRef]

107. Liu, Z.; Dong, L.; Jia, K.; Zhan, H.; Zhang, Z.; Shah, N.P.; Tao, X.; Wei, H. Sulfonation of Lactobacillus plantarum WLPL04 exopolysaccharide amplifies its antioxidant activities in vitro and in a Caco-2 cell model. J. Dairy Sci. 2019, 102, 5922-5932. [CrossRef]

108. Sun, M.; Liu, W.; Song, Y.; Tuo, Y.; Mu, G.; Ma, F. The Effects of Lactobacillus plantarum-12 Crude Exopolysaccharides on the Cell Proliferation and Apoptosis of Human Colon Cancer (HT-29) Cells. Probiotics Antimicrob. Proteins 2021, 13, 413-421. [CrossRef]

109. Wang, K.; Li, W.; Rui, X.; Chen, X.; Jiang, M.; Dong, M. Characterization of a novel exopolysaccharide with antitumor activity from Lactobacillus plantarum 70810. Int. J. Biol. Macromol. 2014, 63, 133-139. [CrossRef]

110. Donlan, R.M. Biofilms: Microbial life on surfaces. Emerg. Infect. Dis. 2002, 8, 881-890. [CrossRef]

111. Du, H.; Yang, J.; Lu, X.; Lu, Z.; Bie, X.; Zhao, H.; Zhang, C.; Lu, F. Purification, Characterization, and Mode of Action of Plantaricin GZ1-27, a Novel Bacteriocin against Bacillus cereus. J. Agric. Food Chem. 2018, 66, 4716-4724. [CrossRef]

112. Schlech, W.F., III. Foodborne listeriosis. Clin. Infect. Dis. Off. Publ. Infect. Dis. Soc. Am. 2000, 31, 770-775. [CrossRef]

113. Arrioja-Bretón, D.; Mani-López, E.; Bach, H.; López-Malo, A. Antimicrobial activity of protein-containing fractions isolated from Lactobacillus plantarum NRRL B-4496 culture. Braz. J. Microbiol. 2020, 51, 1289-1296. [CrossRef]

114. Twomey, E.; Hill, C.; Field, D.; Begley, M. Recipe for Success: Suggestions and Recommendations for the Isolation and Characterisation of Bacteriocins. Int. J. Microbiol. 2021, 2021, 9990635. [CrossRef]

115. Park, D.M.; Bae, J.H.; Kim, M.S.; Kim, H.; Kang, S.D.; Shim, S.; Lee, D.; Seo, J.H.; Kang, H.; Han, N.S. Suitability of Lactobacillus plantarum SPC-SNU 72-2 as a Probiotic Starter for Sourdough Fermentation. J. Microbiol. Biotechnol. 2019, 29, 1729-1738. [CrossRef]

116. Milillo, S.R.; Friedly, E.C.; Saldivar, J.C.; Muthaiyan, A.; O’Bryan, C.; Crandall, P.G.; Johnson, M.G.; Ricke, S.C. A review of the ecology, genomics, and stress response of Listeria innocua and Listeria monocytogenes. Crit. Rev. Food Sci. Nutr. 2012, 52, 712-725. [CrossRef]

117. Dhanasekara, C.S.; Marschke, B.; Morris, E.; Kahathuduwa, C.N.; Dissanaike, S. Global patterns of necrotizing soft tissue infections: A systematic review and meta-analysis. Surgery 2021. [CrossRef]

118. Qiu, Y.; Xu, D.; Xia, X.; Zhang, K.; Adil, R.M.; Batool, Z.; Wang, J. Five major two components systems of Staphylococcus aureus for adaptation in diverse hostile environment. Microb. Pathog. 2021, 159, 105119. [CrossRef]

119. Allocati, N.; Masulli, M.; Alexeyev, M.F.; Di Ilio, C. Escherichia coli in Europe: An overview. Int. J. Environ. Res. Public Health 2013, 10, 6235-6254. [CrossRef]

120. Jesser, K.J.; Levy, K. Updates on defining and detecting diarrheagenic Escherichia coli pathotypes. Curr. Opin. Infect. Dis. 2020, 33, 372-380. [CrossRef]

121. Liu, H.; Zhang, L.; Yi, H.; Han, X.; Chi, C. Identification and characterization of plantaricin Q7, a novel plantaricin produced by Lactobacillus plantarum Q7. LWT-Food Sci. Technol. 2016, 71, 386-390. [CrossRef]

122. Jiang, H.; Li, P.; Gu, Q. Heterologous expression and purification of plantaricin NC8, a two-peptide bacteriocin against Salmonella spp. from Lactobacillus plantarum ZJ316. Protein Expr. Purif. 2016, 127, 28-34. [CrossRef]

123. Sihombing, D.E.; Arief, I.I.; Budiarti, S. Application of antimicrobial agents produced by Lactobacillus plantarum IIA-1A5 as natural preservative on beef during room temperature storage. Adv. J. Food Sci. Technol. 2015, 8, 251-255. [CrossRef]

124. Chen, L.; Gu, Q.; Li, P.; Li, Y.; Song, D.; Yang, J. Purification and characterization of plantaricin ZJ316, a novel bacteriocin against listeria monocytogenes from lactobacillus plantarum ZJ316. J. Food Prot. 2018, 81, 1929-1935. [CrossRef]

125. de Jong, H.K.; Parry, C.M.; van der Poll, T.; Wiersinga, W.J. Host-pathogen interaction in invasive Salmonellosis. PLoS Pathog. 2012, 8, e1002933. [CrossRef]

126. Gal-Mor, O.; Boyle, E.C.; Grassl, G.A. Same species, different diseases: How and why typhoidal and non-typhoidal Salmonella enterica serovars differ. Front. Microbiol. 2014, 5, 391. [CrossRef]

127. Bartkiene, E.; Ruzauskas, M.; Bartkevics, V.; Pugajeva, I.; Zavistanaviciute, P.; Starkute, V.; Zokaityte, E.; Lele, V.; Dauksiene, A.; Grashorn, M.; et al. Study of the antibiotic residues in poultry meat in some of the EU countries and selection of the best compositions of lactic acid bacteria and essential oils against Salmonella enterica. Poult. Sci. 2020, 99, 4065-4076. [CrossRef]

128. Ehling-Schulz, M.; Lereclus, D.; Koehler, T.M. The Bacillus cereus Group: Bacillus Species with Pathogenic Potential. Microbiol. Spectr. 2019, 7, 7. [CrossRef] 
129. Stenfors Arnesen, L.P.; Fagerlund, A.; Granum, P. From soil to gut: Bacillus cereus and its food poisoning toxins. FEMS Microbiol. Rev. 2008, 32, 579-606. [CrossRef]

130. Lai, K.K. Enterobacter sakazakii infections among neonates, infants, children, and adults. Case reports and a review of the literature. Medicine 2001, 80, 113-122. [CrossRef]

131. Bowen, A.B.; Braden, C. Invasive Enterobacter sakazakii disease in infants. Emerg. Infect. Dis. 2006, 12, 1185-1189. [CrossRef]

132. Gales, A.C.; Jones, R.N.; Turnidge, J.; Rennie, R.; Ramphal, R. Characterization of Pseudomonas aeruginosa isolates: Occurrence rates, antimicrobial susceptibility patterns, and molecular typing in the global SENTRY Antimicrobial Surveillance Program, 1997-1999. Clin. Infect. Dis. 2001, 32, S146-S155. [CrossRef]

133. Azam, M.W.; Khan, A.U. Updates on the pathogenicity status of Pseudomonas aeruginosa. Drug Discov. Today 2019, 24, 350-359. [CrossRef]

134. Lei, S.; Zhao, R.; Sun, J.; Ran, J.; Ruan, X.; Zhu, Y. Partial purification and characterization of a broad-spectrum bacteriocin produced by a Lactobacillus plantarum zrx03 isolated from infant's feces. Food Sci. Nutr. 2020, 8, 2214-2222. [CrossRef] [PubMed]

135. Pei, J.; Li, X.; Han, H.; Tao, Y. Purification and characterization of plantaricin SLG1, a novel bacteriocin produced by Lb. plantarum isolated from yak cheese. Food Control 2018, 84, 111-117. [CrossRef]

136. Zhao, S.; Han, J.; Bie, X.; Lu, Z.; Zhang, C.; Lv, F. Purification and Characterization of Plantaricin JLA-9: A Novel Bacteriocin against Bacillus spp. Produced by Lactobacillus plantarum JLA-9 from Suan-Tsai, a Traditional Chinese Fermented Cabbage. J. Agric. Food Chem. 2016, 64, 2754-2764. [CrossRef]

137. Song, D.F.; Zhu, M.Y.; Gu, Q. Purification and characterization of plantaricin ZJ5, a new bacteriocin produced by Lactobacillus plantarum ZJ5. PLoS ONE 2014, 9, e105549. [CrossRef]

138. Lin, C.J.; Pan, C.F.; Chuang, C.K.; Sun, F.J.; Wang, D.J.; Chen, H.H.; Liu, H.L.; Wu, C.J. P-cresyl sulfate is a valuable predictor of clinical outcomes in pre-ESRD patients. BioMed Res. Int. 2014, 2014, 526932. [CrossRef]

139. Kumar, V.; Sheoran, P.; Gupta, A.; Yadav, J.P.; Tiwari, S.K. Antibacterial property of bacteriocin produced by Lactobacillus plantarum LD4 isolated from a fermented food. Ann. Microbiol. 2016, 66, 1431-1440. [CrossRef]

140. Hu, M.; Zhao, H.; Zhang, C.; Yu, J.; Lu, Z. Purification and characterization of plantaricin 163, a novel bacteriocin produced by Lactobacillus plantarum 163 isolated from traditional Chinese fermented vegetables. J. Agric. Food Chem. 2013, 61, 11676-11682. [CrossRef]

141. Choi, E.A.; Chang, H.C. Cholesterol-lowering effects of a putative probiotic strain Lactobacillus plantarum EM isolated from kimchi. LWT-Food Sci. Technol. 2015, 62, 210-217. [CrossRef]

142. Qian, Z.; Zhu, H.; Zhao, D.; Yang, P.; Gao, F.; Lu, C.; Yin, Y.; Kan, S.; Chen, D. Probiotic lactobacillus Sp. Strains inhibit growth, adhesion, biofilm formation, and gene expression of bacterial vaginosis-inducing gardnerella vaginalis. Microorganisms 2021, 9, 728. [CrossRef]

143. Qian, Z.; Zhao, D.; Yin, Y.; Zhu, H.; Chen, D. Antibacterial Activity of Lactobacillus Strains Isolated from Mongolian Yogurt against Gardnerella vaginalis. BioMed Res. Int. 2020, 2020, 3548618. [CrossRef] [PubMed]

144. Goel, A.; Halami, P.M.; Tamang, J.P. Genome Analysis of Lactobacillus plantarum Isolated From Some Indian Fermented Foods for Bacteriocin Production and Probiotic Marker Genes. Front. Microbiol. 2020, 11, 40. [CrossRef] [PubMed]

145. Becker, K.; Rutsch, F.; Uekötter, A.; Kipp, F.; König, J.; Marquardt, T.; Peters, G.; von Eiff, C. Kocuria rhizophila adds to the emerging spectrum of micrococcal species involved in human infections. J. Clin. Microbiol. 2008, 46, 3537-3539. [CrossRef] [PubMed]

146. Choi, W.J.; Dong, H.J.; Jeong, H.U.; Jung, H.H.; Kim, Y.H.; Kim, T.H. Antiobesity Effects of Lactobacillus plantarum LMT1-48 Accompanied by Inhibition of Enterobacter cloacae in the Intestine of Diet-Induced Obese Mice. J. Med. Food 2019, 22, 560-566. [CrossRef]

147. Kwak, M.K.; Liu, R.; Kwon, J.O.; Kim, M.K.; Kim, A.H.J.; Kang, S.O. Cyclic dipeptides from lactic acid bacteria inhibit proliferation of the influenza a virus. J. Microbiol. 2013, 51, 836-843. [CrossRef] [PubMed]

148. Sunmola, A.A.; Ogbole, O.O.; Faleye, T.O.C.; Adetoye, A.; Adeniji, J.A.; Ayeni, F.A. Antiviral potentials of Lactobacillus plantarum, Lactobacillus amylovorus, and Enterococcus hirae against selected Enterovirus. Folia Microbiol. 2019, 64, 257-264. [CrossRef]

149. Wang, K.; Ran, L.; Yan, T.; Niu, Z.; Kan, Z.; Zhang, Y.; Yang, Y.; Xie, L.; Huang, S.; Yu, Q.; et al. Anti-TGEV Miller Strain Infection Effect of Lactobacillus plantarum Supernatant Based on the JAK-STAT1 Signaling Pathway. Front. Microbiol. 2019, 10, 2540. [CrossRef]

150. Arena, M.P.; Elmastour, F.; Sane, F.; Drider, D.; Fiocco, D.; Spano, G.; Hober, D. Inhibition of coxsackievirus B4 by Lactobacillus plantarum. Microbiol. Res. 2018, 210, 59-64. [CrossRef]

151. Sirichokchatchawan, W.; Temeeyasen, G.; Nilubol, D.; Prapasarakul, N. Protective Effects of Cell-Free Supernatant and Live Lactic Acid Bacteria Isolated from Thai Pigs Against a Pandemic Strain of Porcine Epidemic Diarrhea Virus. Probiotics Antimicrob. Proteins 2018, 10, 383-390. [CrossRef]

152. Kim, K.; Lee, G.; Thanh, H.D.; Kim, J.H.; Konkit, M.; Yoon, S.; Park, M.; Yang, S.; Park, E.; Kim, W. Exopolysaccharide from Lactobacillus plantarum LRCC5310 offers protection against rotavirus-induced diarrhea and regulates inflammatory response. J. Dairy Sci. 2018, 101, 5702-5712. [CrossRef]

153. Cantú-Bernal, S.; Domínguez-Gámez, M.; Medina-Peraza, I.; Aros-Uzarraga, E.; Ontiveros, N.; Flores-Mendoza, L.; Gomez-Flores, R.; Tamez-Guerra, P.; González-Ochoa, G. Enhanced Viability and Anti-rotavirus Effect of Bifidobacterium longum and Lactobacillus plantarum in Combination With Chlorella sorokiniana in a Dairy Product. Front. Microbiol. 2020, 11, 875. [CrossRef] [PubMed] 
154. Shin, D.Y.; Yi, D.Y.; Jo, S.; Lee, Y.M.; Kim, J.H.; Kim, W.; Park, M.R.; Yoon, S.M.; Kim, Y.; Yang, S.; et al. Effect of a new Lactobacillus plantarum product, LRCC5310, on clinical symptoms and virus reduction in children with rotaviral enteritis. Medicine 2020, 99, e22192. [CrossRef] [PubMed]

155. Cave, R.; Cole, J.; Mkrtchyan, H.V. Surveillance and prevalence of antimicrobial resistant bacteria from public settings within urban built environments: Challenges and opportunities for hygiene and infection control. Environ. Int. 2021, $157,106836$. [CrossRef]

156. O'Neill, J. Tackling Drug-Resistant Infections Globally: Final Report and Recommendations; Government of the United Kingdom: London, UK, 2016.

157. Huang, H.C.; Lee, I.J.; Huang, C.; Chang, T.M. Lactic Acid Bacteria and Lactic Acid for Skin Health and Melanogenesis Inhibition. Curr. Pharm. Biotechnol. 2020, 21, 566-577. [CrossRef] [PubMed]

158. Ramos, A.N.; Sesto Cabral, M.E.; Noseda, D.; Bosch, A.; Yantorno, O.M.; Valdez, J.C. Antipathogenic properties of Lactobacillus plantarum on Pseudomonas aeruginosa: The potential use of its supernatants in the treatment of infected chronic wounds. Wound Repair Regen. 2012, 20, 552-562. [CrossRef]

159. Beck, B.R.; Park, G.-S.; Lee, Y.H.; Im, S.; Jeong, D.Y.; Kang, J. Whole genome analysis of Lactobacillus plantarum strains isolated from kimchi and determination of probiotic properties to treat mucosal infections by Candida albicans and Gardnerella vaginalis. Front. Microbiol. 2019, 10, 433. [CrossRef]

160. Vicariotto, F.; Mogna, L.; Del Piano, M. Effectiveness of the two microorganisms Lactobacillus fermentum LF15 and Lactobacillus plantarum LP01, formulated in slow-release vaginal tablets, in women affected by bacterial vaginosis: A pilot study. J. Clin. Gastroenterol. 2014, 48, 106-112. [CrossRef]

161. Zhai, Q.; Yu, L.; Li, T.; Zhu, J.; Zhang, C.; Zhao, J.; Zhang, H.; Chen, W. Effect of dietary probiotic supplementation on intestinal microbiota and physiological conditions of Nile tilapia (Oreochromis niloticus) under waterborne cadmium exposure. Antonie VanLeeuwenhoek 2017, 110, 501-513. [CrossRef]

162. Zang, L.; Ma, Y.; Huang, W.; Ling, Y.; Sun, L.; Wang, X.; Zeng, A.; Dahlgren, R.A.; Wang, C.; Wang, H. Dietary Lactobacillus plantarum ST-III alleviates the toxic effects of triclosan on zebrafish (Danio rerio) via gut microbiota modulation. Fish Shellfish. 2019, 84, 1157-1169. [CrossRef] [PubMed]

163. McNicholl, A.G.; Molina-Infante, J.; Lucendo, A.J.; Calleja, J.L.; Pérez-Aisa, Á.; Modolell, I.; Aldeguer, X.; Calafat, M.; Comino, L.; Ramas, M.; et al. Probiotic supplementation with Lactobacillus plantarum and Pediococcus acidilactici for Helicobacter pylori therapy: A randomized, double-blind, placebo-controlled trial. Helicobacter 2018, 23, e12529. [CrossRef]

164. Kujawa-Szewieczek, A.; Adamczak, M.; Kwiecień, K.; Dudzicz, S.; Gazda, M.; Więcek, A. The effect of Lactobacillus plantarum 299v on the incidence of Clostridium difficile infection in high risk patients treated with antibiotics. Nutrients 2015, 7, 10179-10188. [CrossRef]

165. Vicariotto, V. Effectiveness of an association of a cranberry dry extract, D-mannose, and the two microorganisms Lactobacillus plantarum LP01 and Lactobacillus paracasei LPC09 in women affected by cystitis: A pilot study. J. Clin. Gastroenterol. 2014, 48, S96-S101. [CrossRef] [PubMed]

166. Bosch, M.; Fuentes, M.C.; Audivert, S.; Bonachera, M.A.; Peiró, S.; Cuñé, J. Lactobacillus plantarum CECT 7527, 7528 and 7529: Probiotic candidates to reduce cholesterol levels. J. Sci. Food Agric. 2014, 94, 803-809. [CrossRef] [PubMed]

167. Alisi, A.; Bedogni, G.; Baviera, G.; Giorgio, V.; Porro, E.; Paris, C.; Giammaria, P.; Reali, L.; Anania, F.; Nobili, V. Randomised clinical trial: The beneficial effects of VSL\#3 in obese children with non-alcoholic steatohepatitis. Aliment. Pharmacol. Ther. 2014, 39, 1276-1285.

168. Miraghajani, M.; Dehsoukhteh, S.S.; Rafie, N.; Hamedani, S.G.; Sabihi, S.; Ghiasvand, R. Potential mechanisms linking probiotics to diabetes: A narrative review of the literature. Sao Paulo Med. J. 2017, 135, 169-178. [CrossRef] [PubMed]

169. Kaźmierczak-Siedlecka, K.; Daca, A.; Folwarski, M.; Witkowski, J.M.; Bryl, E.; Makarewicz, W. The role of Lactobacillus plantarum $299 \mathrm{v}$ in supporting treatment of selected diseases. Cent. Eur. J. Immunol. 2020, 45, 488-493. [CrossRef]

170. Rudzki, L.; Ostrowska, L.; Pawlak, D.; Małus, A.; Pawlak, K.; Waszkiewicz, N.; Szulc, A. Probiotic Lactobacillus Plantarum $299 \mathrm{v}$ decreases kynurenine concentration and improves cognitive functions in patients with major depression: A double-blind, randomized, placebo controlled study. Psychoneuroendocrinology 2019, 100, 213-222. [CrossRef]

171. Siezen, R.J.; van Hylckama Vlieg, J.E.T. Genomic diversity and versatility of Lactobacillus plantarum, a natural metabolic engineer. Microb. Cell Fact. 2011, 10, S3. [CrossRef]

172. Benítez-Chao, D.F.; León-Buitimea, A.; Lerma-Escalera, J.A.; Morones-Ramírez, J.R. Bacteriocins: An Overview of Antimicrobial, Toxicity, and Biosafety Assessment by in vivo Models. Front. Microbiol. 2021, 12, 630695. [CrossRef]

173. Fu, T.; Liu, Y.M. Antibacterial effect of bacteriocin isolated from lactobacillus plantarum ATCC 8014 on postoperative infection of mandibular fracture in vivo. J. Craniofac. Surg. 2017, 28, 679-682. [CrossRef]

174. Xu, Z.; Li, J.; Zhou, X.; Dai, J.; Zhang, J.; Huang, Y.; Xu, N. The combined use of tea polyphenols and lactobacillus plantarum ST8SH bacteriocin in a rabbit model of infection following femoral fracture with internal fixation. Med. Sci. Monit. 2019, 25, 312-317. [CrossRef]

175. Fu, T.; Yu, M.; Yan, Q.; Liu, Y.M. Bacteriocin Isolated from Lactobacillus Rhamnosus L34 Has Antibacterial Effects in a Rabbit Model of Infection After Mandible Fracture Fixation. Med. Sci. Monit. 2018, 24, 8009-8014. [CrossRef] [PubMed] 
176. Valdéz, J.C.; Peral, M.C.; Rachid, M.; Santana, M.; Perdigon, G. Interference of Lactobacillus plantarum with Pseudomonas aeruginosa in vitro and in infected burns: The potential use of probiotics in wound treatment. Clin. Microbiol. Infect. 2005, 11, 472-479. [CrossRef] [PubMed]

177. Lopes, E.G.; Moreira, D.A.; Gullón, P.; Gullón, B.; Cardelle-Cobas, A.; Tavaria, F.K. Topical application of probiotics in skin: Adhesion, antimicrobial and antibiofilm in vitro assays. J. Appl. Microbiol. 2017, 122, 450-461. [CrossRef]

178. Nam, Y.; Kim, J.; Baek, J.; Kim, W. Improvement of Cutaneous Wound Healing via Topical Application of Heat-Killed Lactococcus chungangensis CAU 1447 on Diabetic Mice. Nutrients 2021, 13, 2666. [CrossRef] [PubMed]

179. van Zyl, W.F.; Deane, S.M.; Dicks, L.M.T. Bacteriocin production and adhesion properties as mechanisms for the anti-listerial activity of Lactobacillus plantarum 423 and Enterococcus mundtii ST4SA. Benef. Microbes 2019, 10, 329-349. [CrossRef]

180. Sharafi, H.; Maleki, H.; Ahmadian, G.; Zahiri, H.S.; Sajedinejad, N.; Houshmand, B.; Vali, H.; Noghabi, K.A. Antibacterial activity and probiotic potential of Lactobacillus plantarum HKN01: A new insight into the morphological changes of antibacterial compound-treated Escherichia coli by electron microscopy. J. Microbiol. Biotechnol. 2013, 23, 225-236. [CrossRef]

181. Sunanliganon, C.; Thong-Ngam, D.; Tumwasorn, S.; Klaikeaw, N. Lactobacillus plantarum B7 inhibits Helicobacter pylori growth and attenuates gastric inflammation. World J. Gastroenterol. 2012, 18, 2472-2480. [CrossRef]

182. Chomwong, S.; Charoensapsri, W.; Amparyup, P.; Tassanakajon, A. Two host gut-derived lactic acid bacteria activate the proPO system and increase resistance to an AHPND-causing strain of Vibrio parahaemolyticus in the shrimp Litopenaeus vannamei. Dev. Comp. Immunol. 2018, 89, 54-65. [CrossRef]

183. O'Toole, P.W.; Marchesi, J.R.; Hill, C. Next-generation probiotics: The spectrum from probiotics to live biotherapeutics. Nat. Microbiol. 2017, 2, 17057. [CrossRef] [PubMed]

184. Bui, T.P.N.; de Vos, W.M. Next-generation therapeutic bacteria for treatment of obesity, diabetes, and other endocrine diseases. Best Pract. Res. Clin. Endocrinol. Metab. 2021, 35, 101504. [CrossRef] [PubMed] 